\title{
Hydrogen Peroxide Dependent cis-Dihydroxylation of Benzoate by Fully Oxidized Benzoate 1,2-Dioxygenase ${ }^{\dagger}$
}

\author{
Matthew B. Neibergall§, Audria Stubna ${ }^{\natural}$, Yasmina Mekmouche§,\#, Eckard Münck ${ }^{\mathfrak{a}}$, and John \\ D. Lipscomb§, \\ \$Department of Biochemistry, Molecular Biology, and Biophysics, and Center for Metals in \\ Biocatalysis, University of Minnesota, Minneapolis, MN 55455 \\ ${ }^{a}$ Department of Chemistry, Carnegie Mellon University, Pittsburgh, PA 15213
}

\section{Abstract}

Rieske dioxygenases catalyze the reductive activation of $\mathrm{O}_{2}$ for the formation of $c i s$-dihydrodiols from unactivated aromatic compounds. It is known that $\mathrm{O}_{2}$ is activated at a mononuclear non-heme iron site utilizing electrons supplied by a nearby Rieske iron sulfur cluster. However, it is controversial whether the reactive species is an Fe(III)-(hydro)peroxo or an Fe(II)-(hydro)peroxo (or electronically equivalent species formed by breaking the $\mathrm{O}-\mathrm{O}$ bond). Here it is shown that benzoate 1,2-dioxygenase (BZDO) prepared in a form with the Rieske cluster oxidized and the mononuclear iron in the $\mathrm{Fe}$ (III) state can utilize $\mathrm{H}_{2} \mathrm{O}_{2}$ as a source of reduced oxygen to form the correct cisdihydrodiol product from benzoate. The reaction approaches stoichiometric yield relative to the mononuclear Fe(III) concentration, being limited to a single turnover by inefficient product released from the Fe(III)-product complex. EPR and Mössbauer studies show that the iron remains ferric throughout this single turnover "peroxide shunt" reaction. These results strongly support Fe(III)(hydro)peroxo ( or $\mathrm{Fe}(\mathrm{V})$-oxo-hydroxo) as the reactive species because there is no source of additional reducing equivalents to form the Fe(II)-(hydro)peroxo state. This conclusion could be further tested in the case of BZDO because the peroxide shunt occurs very slowly compared with normal turnover, allowing the reactive intermediate to be trapped for spectroscopic analysis. We attribute the slow reaction rate to a forced change in the normally strict order of the substrate binding and enzyme reduction steps that regulate the catalytic cycle. The reactive intermediate is a high-spin ferric species exhibiting an unusual negative zero field splitting and other EPR and Mössbauer spectroscopic properties reminiscent of previously characterized side-on-bound peroxide adducts of $\mathrm{Fe}$ (III) model complexes. If the species in BZDO is a similar adduct, its isomer shift is most consistent with an Fe (III)-hydroperoxo reactive state.

Rieske nonheme iron dioxygenases catalyze the stereo- and regio-specific, $\mathrm{O}_{2}$-dependent conversion of aromatic substrates into cis-dihydrodiols, thereby initiating the transformation of relatively unreactive aromatic molecules into useful carbon sources for bacteria. The introduction of oxygen atoms into organic substrates in this way is not observed for any other

\footnotetext{
${ }^{\dagger}$ This work was supported by National Institutes of Health (NIH) Grants GM-24689 (J.D.L.) and GM-22701 (E.M.). M.B.N. was supported in part by NIH Training Grant GM-08277.

*To whom correspondence should be addressed at the Department of Biochemistry, Molecular Biology, and Biophysics, University of Minnesota, 6-155 Jackson Hall, 321 Church St. SE, Minneapolis, MN 55455. E-mail: E-mail: lipsc001 @ tc.umn.edu Telephone: (612) 625-6454. Fax: (612) 624-5121.

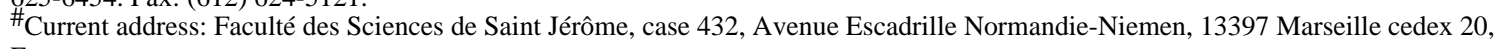
France

SUPPLEMENTAL INFORMATION AVAILABLE

The methods for and results of DFT calculations for a fifteen possible structures for intermediate BZDOP are presented. This material is available free of charge via the internet at http://pubs.acs.org.
} 
enzyme class, suggesting that Rieske dioxygenases use a novel oxygen activation and/or insertion mechanism. Despite substantial progress in understanding the structure, regulation, and kinetics of these systems in recent years, a consensus has not been reached on the chemical steps in this mechanism. A thorough understanding of the mechanism may lead to improved processes for the biodegradation of recalcitrant aromatic pollutants, as well as environmentally friendly routes to chiral precursor compounds for synthetic applications $(1,2)$.

Benzoate 1,2-dioxygenase (BZDOS) ${ }^{1}$ is a typical Rieske dioxygenase system that converts benzoic acid into 1-carboxy-1,2-cis-dihydroxycyclohexa-3,5-diene (benzoate cis-diol) (3-5). The overall reaction stoichiometry requires one molecule of $\mathrm{O}_{2}$ and two electrons from NADH to form the cis-dihydrodiol product as shown below.
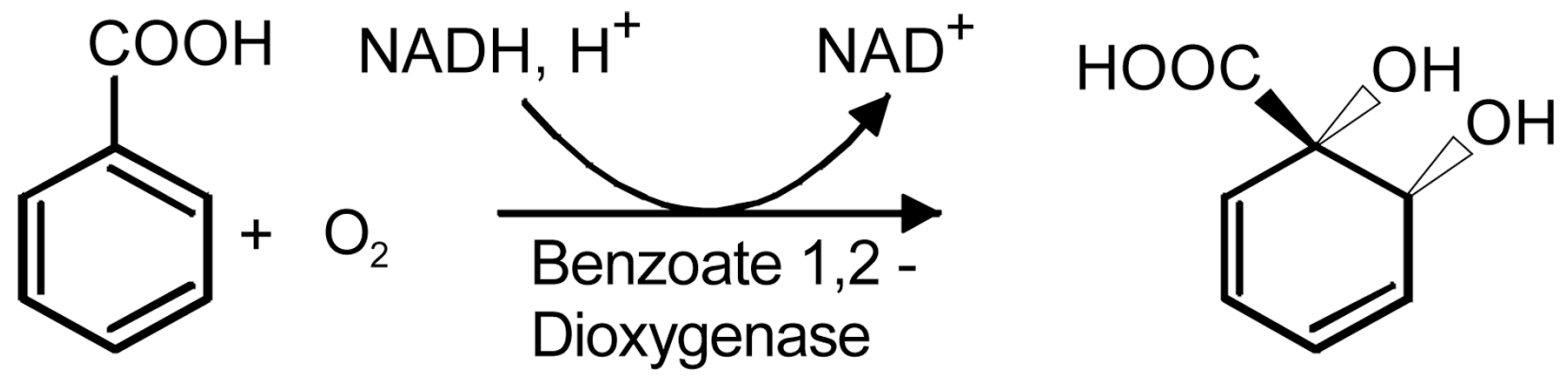

BZDOS is the archetypal member of the Benzoate/Toluate Rieske dioxygenase subgroup and is composed of a reductase (BZDR) and an oxygenase (BZDO) component $(1,3,6)$. BZDR is a $38 \mathrm{kD}$ protein containing an $\mathrm{FAD}$ and a $[2 \mathrm{Fe}-2 \mathrm{~S}]$ cluster with all cysteine ligation (7). BZDR is reduced by NADH and transfers electrons in a stepwise manner to the Rieske cluster of the oxygenase component during turnover $(8,9)$. BZDO is a $200 \mathrm{kD}$ multimeric protein with an $(\alpha \beta)_{3}$ quaternary structure (3). Each $\alpha$ subunit contains a mononuclear nonheme iron active site and a Rieske-type [2Fe-2S] cluster (10-14). Spectroscopic studies demonstrate that substrate binding and oxygen activation occur at the mononuclear iron center $(3,15,16)$. The $\mathrm{X}$-ray crystal structures of related oxygenases also demonstrate substrate binding near the mononuclear iron and strongly suggest that electron transfer to this center occurs from the Rieske cluster located in another $\alpha$-subunit across the subunit boundary $(10-13,17)$.

The metal site composition for BZDO suggests that three oxidation states can be stabilized as indicated below:

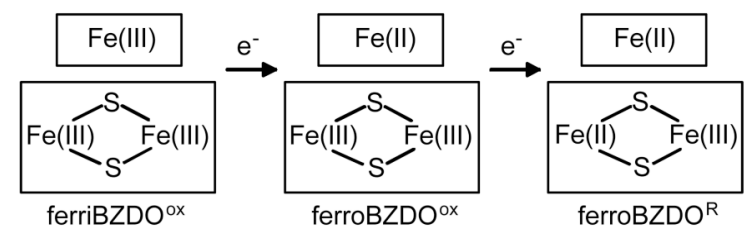

The fourth potential state with the Rieske cluster reduced and the mononuclear iron in the oxidized state is not stable due to the relative redox potentials of the metal centers. Our previous studies demonstrated that BZDO alone, if first chemically reduced to the fully reduced ferroBZDO ${ }^{\mathrm{R}}$ state, can activate $\mathrm{O}_{2}$ and generate the cis-dihydrodiol product in a single turnover

\footnotetext{
${ }^{1}$ Abbreviations: MOPS, 3-(N-morpholino)propanesulfonic acid; MSB, Hutner's mineral salts base; BZDOS, benzoate 1,2- dioxygenase system; BZDO, oxygenase component of BZDOS; BZDR, reductase component of BZDOS; benzoate cis-diol, 1-carboxy-1,2-cisdihydroxycyclohexa-3,5-diene; NDO, oxygenase component of the naphthalene 1,2-dioxygenase system; PDOS, phthalate dioxygenase system; PDO, oxygenase component of PDOS; EDTA, ethylenediaminetetraacetic acid.
} 
reaction (3). Following the single turnover, the enzyme was found to be in the fully oxidized ferriBZDO ${ }^{\text {ox }}$ state with the product largely retained in the active site, indicating that the mononuclear iron and Rieske centers each provide one of the two electrons required by the reaction stoichiometry. The same was found to be true for naphthalene 1,2-dioxygenase oxygenase component (NDO), which produced essentially stoichiometric yield in a single turnover based on the number of populated mononuclear sites present (18).

The observation that the two electrons present in the Rieske and mononuclear iron centers of NDO and BZDO are utilized during a single turnover was interpreted to support the mechanism shown in Scheme 1 in which $\mathrm{O}_{2}$ is activated by being reduced to the peroxo state after binding to the mononuclear iron (Fe(III)-(hydro)peroxo). This state might then react directly with bound substrate (pathway 1), or O-O bond cleavage might occur to yield a formal $\mathrm{Fe}(\mathrm{V})$-oxohydroxo species prior to reaction (pathway 2). An alternative mechanism, shown in Scheme 1 , pathway 3 , invokes an additional step in which an electron is donated to the initially formed $\mathrm{Fe}(\mathrm{III})$-peroxo species to yield an $\mathrm{Fe}$ (II)-peroxo intermediate that could react either directly or as an $\mathrm{Fe}$ (IV)-oxo-hydroxo species after $\mathrm{O}-\mathrm{O}$ bond cleavage. The latter mechanism is supported by studies of the phthalate dioxygenase system (PDOS) in which it was reported that, while a product-yielding single turnover occurred as observed for NDO and BZDO, the mononuclear iron was left in the Fe(II) state after the reaction $(19,20)$. This suggested that an additional electron was transferred to the mononuclear site at some stage of the catalytic cycle. It was postulated that the source of this electron is a Rieske cluster from another $\alpha$-subunit beyond that normally paired with a given mononuclear center. While this is feasible in the case of phthalate dioxygenase due to its atypical quaternary structure ${ }^{2}$ that might allow closer proximity of the ancillary Rieske cluster, it seems unlikely that two different mechanisms could result in the same final product, given the unique nature of the catalyzed reaction.

One way to differentiate these mechanistic alternatives is to examine the ability of the Rieske dioxygenases to utilize a peroxide shunt for catalysis in place of the usual reductive $\mathrm{O}_{2}$ activation cycle. In the peroxide shunt, $\mathrm{H}_{2} \mathrm{O}_{2}$ and substrate are incubated with the oxidized enzyme. $\mathrm{H}_{2} \mathrm{O}_{2}$ can, in principle, provide both the oxygen and the 2 electrons required for product formation. Observation of a functional peroxide shunt would support a mechanism as shown in Scheme 1 pathways 1 or 2 in which only two reducing equivalents are required to yield an activated species that can attack an aromatic substrate.

Previously, we demonstrated that ferroNDO ${ }^{\text {ox }}$ reacts with $\mathrm{H}_{2} \mathrm{O}_{2}$ and naphthalene to form the cis-dihydrodiol product in a peroxide shunt reaction where the incorporated oxygen derives from $\mathrm{H}_{2} \mathrm{O}_{2}$ (23). While this supports the mechanism shown in Scheme 1 pathways 1 or 2, two aspects of the reaction prevented drawing an unequivocal conclusion. First, the resting state of NDO is ferroNDO ${ }^{\text {ox }}$ rather than the fully oxidized ferriNDO ${ }^{\mathrm{ox}}$ state. Consequently, a third reducing equivalent is potentially available in the system after adding peroxide. Second, the peroxide shunt results in only a single turnover due to the fact that the mononuclear iron is oxidized to the ferric state at some point. We have shown that this state does not rapidly release product, thereby blocking further turnover (18). Together, these observations show that 3 reducing equivalents are consumed in the single turnover peroxide shunt, which might support Scheme 1 pathway 3 if the presence of the third electron is necessary for the shunt to function. It should be noted, however, that Scheme 1, pathway 3 predicts that the mononuclear iron will remain reduced at the end of the reaction, and thus product should be released and the peroxide shunt should proceed through many turnovers, contrary to what is observed.

Here we approach this problem by examining the peroxide shunt reaction of BZDO. Unlike NDO, BZDO can be isolated with either Fe(II) or Fe(III) in the mononuclear site (3). It is shown

\footnotetext{
${ }^{2} \mathrm{PDO}$ was reported initially to be an $\alpha_{4}$ tetramer $(19,21)$. More recent experiments suggest an $\alpha_{6}$ hexameric structure (22).
} 
that a peroxide shunt reaction initiated from the ferriBZDO ${ }^{\text {ox }}$ form of the enzyme results in benzoate cis-diol formation. Thus, this study provides strong support for an oxygen activation mechanism that does not require a third reducing equivalent to yield a reactive species that is capable of producing the correct $c i s$-dihydrodiol product. In addition, the unique properties of ferriBZDO $^{\text {ox }}$ allow direct characterization of a key reactive intermediate in Rieske dioxygenase catalysis.

\section{MATERIALS and METHODS}

\section{Reagents}

MOPS, sodium benzoate, catalase, chelex-100, and 1,10-phenanthroline were purchased from Sigma-Aldrich. HEPES, $\mathrm{H}_{2} \mathrm{O}_{2}$, EDTA, and $\mathrm{KCN}$ were purchased from Fisher in the highest grade available and used without further purification. Authentic benzoate cis-diol was prepared according to published procedures $(4,24)$. Water was deionized and further purified using a Millipore reverse osmosis system. ${ }^{57} \mathrm{Fe}(95.38 \%)$ was purchased from WEB Research Co. (Edina, Minnesota).

\section{Cell Growth}

Pseudomonas putida mt-2 (ATCC 23973), cured of the TOL plasmid, was grown on modified Hutner's mineral salts base (MSB) supplemented with $5 \mathrm{mM}$ sodium benzoate as the sole carbon source (MSB-benzoate) as described previously (3).

\section{Enzyme Purification}

BZDO was purified from $P$. putida $\mathrm{mt}-2$. FerriBZDO ${ }^{\text {ox }}$ was purified using the previously reported method I (3). FerroBZDO ${ }^{\text {ox }}$ was prepared according to a modified version of method II (3) in which the mononuclear site was depleted of iron using chelators during the initial stages of the purification. $10 \mathrm{mM}$ EDTA and $1 \mathrm{mM}$ 1,10-phenanthroline were included in the buffer used to resuspend the frozen cell paste prior to breaking the cells. The Rieske center is not susceptible to iron removal under these conditions. $1 \mathrm{mM}$ EDTA was added to all other buffers except for that used to develop the Sephacryl S-300 size-exclusion column. Instead, the size-exclusion buffer was treated with chelex-100 prior to use in order to remove trace metals. The purified apo-protein $\left(\mathrm{BZDO}_{\mathrm{apo}}\right.$ ) was then reconstituted with ferrous ammonium sulfate prior to use in experiments (3). BZDR was purified as described previously (3).

\section{Preparation of ${ }^{57} \mathrm{Fe}$ Enriched Enzyme}

${ }^{57} \mathrm{Fe}$-labeled BZDO was purified according to method I from P. putida $\mathrm{mt}-2$ cells grown in MSB-benzoate supplemented with ${ }^{57} \mathrm{Fe}$. To prepare the minimal media, all precursor solutions used in MSB-benzoate were made without the addition of the prescribed iron, and ${ }^{57} \mathrm{Fe}$ was added from a stock solution to a final concentration of $0.4 \mathrm{mg} / \mathrm{L}$. The ${ }^{57} \mathrm{Fe}$ stock solution was prepared by dissolving ${ }^{57} \mathrm{Fe}$ metal in aqua-regia.

\section{BZDOS Assays}

The activity of BZDO was routinely determined by measuring $\mathrm{O}_{2}$ consumption using a polarographic $\mathrm{O}_{2}$ electrode (Hansatech). Standard assay conditions are: 0.1 M MOPS pH 6.9, $0.1 \mathrm{M} \mathrm{NaCl}, 1 \mathrm{mM}$ benzoate, $0.3 \mathrm{mM}$ NADH, $1 \mu \mathrm{M}$ BZDR, $23^{\circ} \mathrm{C}$. The amount of BZDO was adjusted to obtain a sufficient rate for accurate determination, which was usually in the range of $0.1-0.5 \mu \mathrm{M}(\alpha \beta)$. In an experiment described in the Results, BZDO activity was assayed for samples removed from a progressing peroxide shunt reaction. This reaction contained 1.4 $\mu \mathrm{MBZDO}(\alpha \beta)$ and, in some cases, the sample was pretreated with $10 \mu \mathrm{g}$ of catalase to consume $\mathrm{H}_{2} \mathrm{O}_{2}$ carried over from peroxide shunt reaction prior to assay. 
The activity of BZDR was routinely assayed at $23{ }^{\circ} \mathrm{C}$ by following the reduction of $\mathrm{K}_{3} \mathrm{Fe}$ $(\mathrm{CN})_{6}$ spectrophotometrically at $420 \mathrm{~nm}$ (3). In the experiment leading to Figure 4 below, NADH consumption at $23^{\circ} \mathrm{C}$ was monitored spectrophotometrically at $340 \mathrm{~nm}$ in the presence and absence of $\mathrm{H}_{2} \mathrm{O}_{2}$. These reactions contained $2 \mu \mathrm{M}$ BZDR and $300 \mu \mathrm{M}$ NADH in $0.1 \mathrm{M}$ MOPS $\mathrm{pH} 6.9,0.1 \mathrm{M} \mathrm{NaCl}$. In particular, these reactions did not contain a terminal electron acceptor, such as BZDO or $\mathrm{K}_{3} \mathrm{Fe}(\mathrm{CN})_{6}$, nor did they contain catalase.

\section{Iron Determination}

The total iron content of purified BZDO was determined using a Varian SpectrAA-100 atomic absorption spectrometer. The iron content of the Rieske cluster was determined using EPR spectroscopy, making the assumption that all Rieske clusters contain both irons (3). A sample of BZDO was completely reduced by adding an excess of sodium dithionite. The EPR spectrum from the reduced Rieske cluster $(g=2.01,1.91,1,77)$ was quantified according to the method described by Aasa and Vanguard using $\mathrm{Cu}\left(\mathrm{ClO}_{4}\right)_{2}$ as a standard (25). The instrumental parameters used to collect the EPR spectra were: $100 \mathrm{kHz}$ modulation frequency, $10 \mathrm{G}$ modulation amplitude, $5000 \mathrm{G}$ sweep width (center field $=2500 \mathrm{G}$ ), $0.2 \mathrm{~mW}$ microwave power, $20 \mathrm{~K}$. The same conditions were used for the standard, except that the microwave power was reduced to $0.005 \mathrm{~mW}$. The difference in microwave power was accounted for in the spin quantitation. The mononuclear iron content was determined from the difference between the total iron content and the Rieske iron content.

\section{Peroxide Shunt Reactions}

Peroxide shunt reactions were initiated by mixing equal volumes of peroxide and enzyme solutions at $23^{\circ} \mathrm{C}$. The peroxide solution was composed of $0.1 \mathrm{M} \mathrm{H}_{2} \mathrm{O}_{2}, 0.1 \mathrm{M}$ MOPS pH 6.9, and $15 \mathrm{mM}$ benzoate unless otherwise indicated. The enzyme solution was composed of 250 $-300 \mu \mathrm{M}$ BZDO $(\alpha \beta), 0.1 \mathrm{M}$ MOPS $\mathrm{pH} 6.9,15 \mathrm{mM}$ benzoate, and $20 \mathrm{mM} \mathrm{KCN}$, unless otherwise indicated. $\mathrm{KCN}$ is included to suppress a small background catalase activity. The EPR spectrum of ferriBZDO ${ }^{\circ}$ in the presence of $10 \mathrm{mM} \mathrm{KCN}$ is unchanged from that reported previously for a sample that did not contain $\mathrm{KCN}$ (3) suggesting that $\mathrm{CN}^{-}$does not bind to the mononuclear iron. When required, aliquots of the reaction were transferred to EPR tubes and frozen in a dry ice/acetone bath for analysis by EPR spectroscopy. Mössbauer samples were prepared in a similar manner, except that liquid nitrogen was used to freeze the samples. EPR and Mössbauer samples contained 0.7 and $0.95-1.2 \mathrm{mM}$ BZDO $(\alpha \beta)$, respectively. In order to perform product analysis, an equal volume of methanol was added to stop the reaction by precipitating the enzyme. Unless otherwise noted, reactions were stopped at $60 \mathrm{~min}$. Samples were vortexed for $30 \mathrm{~s}$ and centrifuged at $16,000 \times \mathrm{g}$ for $8 \mathrm{~min}$ at room temperature to remove the precipitate. The supernatant was transferred to another sample tube and either analyzed immediately or stored at $-20^{\circ} \mathrm{C}$ until analysis.

\section{Product Analysis by HPLC}

Reaction samples were analyzed on either a Waters Breeze HPLC equipped with a 1525 pump and a 2487 detector or a Beckman System Gold HPLC equipped with a 126 solvent module and a 166 detector module. To obtain diode array spectra of the reaction product, samples were analyzed using a SpectraSystem P4000 HPLC system equipped with a UV6000L diode array detector. The reaction mixture was first acidified by mixing 4 volumes of sample with 1 volume of $24 \% \mathrm{H}_{2} \mathrm{SO}_{4}$ and subsequently separated with an Agilent Zorbax StableBond C-18 column $(4.6 \times 150 \mathrm{~mm}, 5 \mu \mathrm{m})$ using an isocratic method. The solvent composition was $4 \% \mathrm{~A}(0.1 \%$ formic acid in acetonitrile) $/ 96 \% \mathrm{~B}(0.1 \%$ formic acid in water) with a flow rate of $0.5 \mathrm{ml} /$ $\min (\lambda=262 \mathrm{~nm})$. Under these conditions, authentic benzoate cis-diol elutes at $14.3( \pm 0.2)$ minutes. 


\section{Benzoate $\mathrm{K}_{\mathrm{m}}$ Determination}

The dependence of the initial rate of the peroxide shunt reaction on benzoate concentration was fit to a hyperbola using the nonlinear fitting function within Microcal Origin software.

\section{$\mathrm{H}_{2} \mathrm{O}_{2}$ Determination}

The amount of $\mathrm{H}_{2} \mathrm{O}_{2}$ was determined in test samples by measuring the amount of $\mathrm{O}_{2}$ produced from the sample using a calibrated polarographic $\mathrm{O}_{2}$ electrode in the presence of catalase. The assay contained $12.5 \mu \mathrm{g}$ of catalase in $1.0 \mathrm{ml}$ of $50 \mathrm{mM}$ MOPS pH 6.9. Once a stable baseline was observed, $\mathrm{O}_{2}$ production was initiated by adding $20 \mu \mathrm{l}$ of an appropriately diluted test sample. Once the $\mathrm{O}_{2}$ production reached a plateau, the change in $\mathrm{O}_{2}$ concentration was measured.

\section{Spectroscopy}

Electronic absorption spectra were recorded using a Hewlett Packard 8453 diode array spectrophotometer. X-band EPR spectra were recorded using Bruker Elexsys E-500 and Bruker ESP 300 spectrometers equipped with Bruker dual mode cavities and Oxford ESR 910 liquid helium cryostats. Spectra were analyzed as previously described using either WinEPR and SimFonia (Bruker) for spectral integrations and simulations, respectively (18) or the software package SpinCount written by M.P. Hendrich, Carnegie Mellon University. For the latter, quantification of all signals was relative to a CuEDTA spin standard. E/D was determined from the $g$-values as previously described (18).

The Mössbauer spectrometers were of the constant acceleration type and were equipped with Janis SuperVaritemp cryostats. External magnetic fields up to $8.0 \mathrm{~T}$ were applied parallel to the observed $\gamma$-radiation. Isomer shifts are reported relative to iron metal at room temperature. The data were analyzed with the software WMOSS (WEB Research, Inc., Edina, MN).

\section{RESULTS}

\section{Peroxide Shunt Reaction of FerroBZDO ${ }^{\circ x}$}

As shown in Table 1, ferroBZDO ${ }^{\text {ox }}$ forms benzoate cis-diol in a peroxide shunt reaction in a manner analogous to that previously reported for formation of naphthalene cis-diol by ferroNDO ${ }^{\mathrm{ox}}(23)$. The product yield varies substantially from preparation to preparation, but the average yield per occupied mononuclear site is found to be $\sim 60 \%$. As in the NDO case, the product yield from BZDO was not observed to exceed one product per occupied mononuclear iron site for any preparation of the enzyme.

\section{Peroxide Shunt Reaction of FerriBZDOox}

FerriBZDO $^{\text {ox }}$ was shown by EPR and Mössbauer spectroscopies to contain no ferrous ion (see below). This form of the enzyme also yields benzoate cis-diol in a peroxide shunt reaction as shown in Table 1 and Figure 1. Diode array spectra acquired during the HPLC analysis show that benzoate cis-diol is the only species that increases in concentration during the reaction. Again, considerable batch-dependent variation is found in the product yields relative to the BZDO $\alpha \beta$ protomer concentration, but less variation is found relative to the occupied mononuclear iron site concentration. The average yield is this case is $\sim 70 \%$ per occupied mononuclear iron site and did not exceed one product per occupied site in any experiment. ${ }^{3}$ Thus, despite the presence of excess peroxide and benzoate at the start of the reaction, neither

\footnotetext{
${ }^{3}$ The preparation of ferroBZDO ${ }^{\text {OX }}$ requires more steps than that for ferriBZDO ${ }^{\text {ox }}$ and generally results in enzyme with lower specific activity. Thus, it is likely that difference in yields observed between the two forms of BZDO reflect fidelity of the enzyme rather than inherent differences in the peroxide shunt reaction.
} 
form of BZDO is capable of multiple turnover as observed for the ferroNDO ${ }^{\text {ox }}$ peroxide shunt reaction (23).

Benzoate cis-diol was not detected when control samples lacking either $\mathrm{H}_{2} \mathrm{O}_{2}$ or BZDO were analyzed by HPLC (Table 2). Increasing the benzoate concentration above the small amount present in the purified enzyme due to its inclusion in the purification buffers increases the rate at which product is generated (Figure 1, inset). When the initial velocity of product formation is plotted as a function of the initial benzoate concentration, a hyperbolic curve is observed with an apparent $K_{\mathrm{m}}$ of $\sim 1 \mathrm{mM}$ (Figure 2). This value is over 2 orders of magnitude larger than the $K_{\mathrm{m}}$ for benzoate observed in multiple turnover experiments when BZDR and NADH are present $(3.9 \mu \mathrm{M})(6)$.

Figure 3 illustrates that the rate of product formation is also dependent upon the initial $\mathrm{H}_{2} \mathrm{O}_{2}$ concentration. BZDO requires millimolar concentrations of $\mathrm{H}_{2} \mathrm{O}_{2}$ in order to generate benzoate cis-diol in significant yield. Addition of $\mathrm{H}_{2} \mathrm{O}_{2}$ during the initial portion of the reaction increases the rate of product formation. However, when $\mathrm{H}_{2} \mathrm{O}_{2}$ is added after the product formation plateaus, no additional product formation is observed. The limited yield was not due to product degradation because benzoate $c i s$-diol was found to be stable for at least 24 hours in reactions containing $50 \mathrm{mM} \mathrm{H}_{2} \mathrm{O}_{2}$. An accurate dependence of the rate and yield on $\mathrm{H}_{2} \mathrm{O}_{2}$ could not be obtained due to a low background catalase activity that caused significant changes in the $\mathrm{H}_{2} \mathrm{O}_{2}$ present during the reaction at concentrations $<10 \mathrm{mM}$ and slow $(>1 \mathrm{~h})$ degradation of both the enzyme and the product at $\mathrm{H}_{2} \mathrm{O}_{2}$ concentrations $>100 \mathrm{mM}$.

\section{Localization of the Peroxide Shunt Reaction to the BZDO Active Site}

Several molecules were tested as potential effectors of the ferriBZDO ${ }^{\text {ox }}$ peroxide shunt (Table 2). Addition of scavengers of various oxygen radical species such as superoxide dismutase and mannitol exhibited insignificant effects on the shunt yield. These results indicate that diffusible, oxygen-derived radicals are not responsible for the product-forming reaction. Furthermore, benzoate cis-diol was not detected in Fenton reaction mixtures consisting of a buffered solution of benzoate, $\mathrm{Fe}(\mathrm{II})$ and $\mathrm{H}_{2} \mathrm{O}_{2}$. Increasing the occupancy of the mononuclear site by adding ferrous ammonium sulfate to the peroxide shunt reaction resulted in increased product yield, but not above 1 per $\alpha \beta$ protomer. Addition of oxidized BZDR had no effect on the peroxide shunt yield, indicating that it does not play an effector or electron transfer role in the reaction.

\section{Reaction Rates}

Under the standard peroxide shunt reaction conditions described in Materials and Methods, ferriBZDO $^{\text {ox }}$ and ferroBZDO ${ }^{\text {ox }}$ form product at similar maximum initial rates of $0.035 \pm 0.005$ $\min ^{-1}$ and $0.050 \pm 0.005 \mathrm{~min}^{-1}$, respectively. Both of these values are much lower than the turnover number for the optimally reconstituted enzyme system coupled to NADH oxidation at $23{ }^{\circ} \mathrm{C}\left(\sim 27 \mathrm{~s}^{-1}\right)$.

\section{Effects of $\mathrm{H}_{2} \mathrm{O}_{2}$ on the Reconstituted BZDOS}

We examined the effect of $\mathrm{H}_{2} \mathrm{O}_{2}$ on BZDO activity to determine if exposure to high peroxide concentrations alters the enzyme integrity. Aliquots of a progressing BZDO peroxide shunt reaction were removed and assayed for $\mathrm{O}_{2}$ consumption activity in the presence of NADH, BZDR, and benzoate as described in Materials and Methods. Under these assay conditions, the $\mathrm{O}_{2}$ consumption activity decreased to about $20 \%$ of the control level even in the earliest samples evaluated ( $\sim \mathrm{min})$. This might indicate that the $\mathrm{H}_{2} \mathrm{O}_{2}$ damages BZDO, however, treatment of the aliquot samples with catalase to remove $\mathrm{H}_{2} \mathrm{O}_{2}$ prior to the assay restored the activity, showing that the rapid activity loss is not due to BZDO inactivation. Similarly, BZDR remained active in catalase treated aliquots. The origin of the apparent activity loss was identified by monitoring the NADH utilization by BZDR at $340 \mathrm{~nm}$ in the absence of BZDO 
and catalase. NADH was rapidly consumed in the presence of $1 \mathrm{mM} \mathrm{H}_{2} \mathrm{O}_{2}$ but not in its absence (Figure 4). This experiment suggests that BZDR acts as a peroxide reductase, transferring reducing equivalents from NADH to $\mathrm{H}_{2} \mathrm{O}_{2}$.

\section{EPR Spectrum of FerriBZDOox}

The EPR spectrum of resting ferriBZDO ${ }^{\text {ox }}$ is shown in Figure 5A and is characterized by two distinct $S=5 / 2$ high spin ferric species. The EPR spectra of such species are commonly described with the $S=5 / 2$ spin Hamiltonian:

$$
\mathscr{H}_{\mathrm{e}}=\mathrm{D}\left[\mathrm{S}_{\mathrm{z}}^{2}-35 / 12+(\mathrm{E} / \mathrm{D})\left(\mathrm{S}_{\mathrm{x}}^{2}-\mathrm{S}_{\mathrm{y}}^{2}\right)\right]+\mathrm{g}_{0} \beta \mathbf{S} \cdot \mathbf{B}
$$

For $\beta B<<|D|$, it is customary to describe each of the three Kramers doublets of the spin sextet by effective $g$-values $(26,27)$. Because high-spin ferric ions have $g_{0} \approx 2.0$, the effective $g$ values depend only on the rhombicity parameter $\mathrm{E} / \mathrm{D}$, constrained in a proper coordinate system to $0 \leq \mathrm{E} / \mathrm{D} \leq 1 / 3$. The major species ( $\mathrm{E} / \mathrm{D}=0.078, \sim 90 \%$ of the mononuclear iron, $\sim 20 \%$ of the total iron in the sample) exhibits resonances from the ground-state Kramers doublet at $g=$ $7.7,4.1$, and 1.8 and from the middle doublet at $g=5.8$. A second ferric species $(\mathrm{E} / \mathrm{D} \approx 0.33)$ is observed at $g \approx 4.3$ and accounts for roughly $10 \%$ of the EPR visible spins ( $2-3 \%$ of the total iron in the sample). This species was proposed in our previous study to derive from the enzymesubstrate complex (3). Quantification of the $\mathrm{E} / \mathrm{D}=0.078$ signal (see Materials and Methods) shows that it accounts well for the spins expected from the mononuclear site based on the total iron concentration less the concentration of the Rieske center determined from the EPR spectrum of the cluster after reduction. The resting enzyme does not exhibit the $g_{\mathrm{av}} \approx 1.89$ signal characteristic of a reduced Rieske center, indicating that the cluster is oxidized. ${ }^{4}$

\section{Intermediates of the Peroxide Shunt Cycle}

The slow reaction of ferriBZDO ${ }^{\mathrm{ox}}$ with $\mathrm{H}_{2} \mathrm{O}_{2}$ and the presence of ferric ion suggested that the reaction time course could be readily monitored by EPR and Mössbauer spectroscopies with the goal of detecting intermediates in the reaction cycle. Aliquots of a progressing reaction were transferred from the reaction vial to EPR tubes or Mössbauer sample holders and then frozen at desired time points for analysis.

The EPR monitored time course of the peroxide shunt reaction of ferriBZDO ${ }^{\text {ox }}$ is shown in Figure 5 B-D, and the low field region is expanded in Figure 5, inset. Many time-dependent spectroscopic changes are observed in the reaction. The spectrum of the first sample, frozen $30 \mathrm{~s}$ after initiating the reaction, shows that the starting $\mathrm{E} / \mathrm{D}=0.078$ species is replaced by a new high-spin ferric species $\left(\mathrm{E} / \mathrm{D}=0.072\right.$, termed $\left.\mathrm{BZDO}_{\mathrm{O}}\right)$ with resonances at $g=7.55,4.3$ and 1.8 (Figure 5B). After 4 min, $\mathrm{BZDO}_{\mathrm{O}}$ has largely disappeared and a new species with $\mathrm{E} /$ $\mathrm{D}=0.133(g=8.5,3.0,1.5)$, previously assigned as the product complex, begins to appear (Figure 5C). Quantification of all of the species that give a resonance in the $g=7.4$ to 8.4 region shows that only about $25 \%$ of the starting EPR spins from this region are accounted for in this sample. By contrast, there are only minor changes in the intensity of the $E / D=0.33$ species. Over the next 20 minutes, the $\mathrm{E} / \mathrm{D}=0.133$ species increases such that it accounts for approximately $80 \%$ of the starting EPR spins visible in the $g=7.4$ to 8.4 region in the sample used for this experiment. ${ }^{5}$ The minor $\mathrm{E} / \mathrm{D}=0.33$ species continues to be almost unchanged in this time period.

\footnotetext{
${ }^{4}$ In principle, the presence of $\mathrm{Fe}(\mathrm{II})$ in the sample could be assessed by adding NO, which binds strongly to mononuclear Fe(II) in the Rieske dioxygenase enzymes and produces an intense $S=3 / 2$ type EPR spectrum (18). However, we have shown that exposure of ferriBZDO $^{\text {OX }}$ to NO causes the reduction of the mononuclear iron by an unknown mechanism. As a result, the EPR spectrum of the ferric ion in ferriBZDO ${ }^{\mathrm{OX}}$ is lost, and it is replaced by spectra from two similar $\mathrm{S}=3 / 2$ species with $g$-values near 4 and 2 (data not shown).
} 


\section{Mössbauer Spectra of a Novel Reaction Cycle Intermediate}

The decline of as much as $75 \%$ of the EPR intensity around $g=8$ in the 4 min sample indicates that an intermediate (termed $\mathrm{BZDO}_{\mathrm{P}}$ ) forms that is either EPR silent or difficult to detect for other reasons. Mössbauer spectroscopy is well suited to identify the oxidation and spin state of $\mathrm{BZDO}_{\mathrm{P}}$ because iron in all oxidation and spin states can be detected. Figure $6 \mathrm{~A}$ and $\mathrm{B}$ and Figure 7A and B show 4.2 K Mössbauer spectra of two samples collected at $30 \mathrm{~s}$ (sample I) and 4 min (sample II) after addition of peroxide; these correlate in freezing time with the EPR spectra of Figure 5B and C (see Materials and Methods). We have also collected Mössbauer spectra of sample III (Figure 7C) frozen after 20 min. The spectra in Figure 6 and Figure 7 were recorded in parallel applied magnetic field of $50 \mathrm{mT}$ and $8.0 \mathrm{~T}$, respectively. The dominant feature in the center of the spectra originates from the Rieske center. The spectra of this (diamagnetic) cluster, well known from our previous studies, can be simulated with good precision so that its contribution can be subtracted from the spectra to allow the spectra due to the mononuclear iron to be analyzed.

Inspection of the data and, more convincingly, difference spectra of samples I and II show that $\mathrm{BZDO}_{\mathrm{P}}$ does not contribute a quadrupole doublet in zero magnetic field, ruling out commonly encountered EPR silent species such as those with integer or zero electronic spin (e.g. Fe(II) or $\mathrm{Fe}(\mathrm{IV})$ or a coupled $\mathrm{Fe}(\mathrm{III})$-radical center). Such a doublet would have been detected even at only $1-2 \%$ of the total iron. ${ }^{6}$ This shows directly that ferriBZDO ${ }^{\text {ox }}$ contains no high-spin ferrous ion $(<1 \%)$, so the peroxide shunt reaction described above must occur at a ferric mononuclear site. Further, from the analysis of the entire Mössbauer data set, we estimate that ca. $20 \%$ of the total iron is high-spin ferric (see below), in accord with analytical iron analysis for the sample, suggesting that all of the non-Rieske cluster iron is accounted for in the sample.

The EPR and Mössbauer spectra of sample II show that it contains at least four high-spin ferric species. As the magnetic hyperfine interactions of high-spin ferric ions, $\mathrm{A}_{0} \mathbf{S} \cdot \mathbf{I}$, are essentially isotropic, the shape of the Mössbauer spectra of each Kramers doublet is quite predictable if $\mathrm{E} / \mathrm{D}$ is known (27). In the present context, two particular cases are noteworthy. The $\mathrm{M}_{\mathrm{S}}= \pm 5 / 2$ doublet of a species with $\mathrm{E} / \mathrm{D}<0.15$ generally yields a spectrum with six sharp absorption lines. In contrast, the $\mathrm{M}_{\mathrm{S}}= \pm 1 / 2$ doublet for $\mathrm{E} / \mathrm{D} \approx 0.08$ (effective g-values of 7.7, 4.1, 1.8) yields broad Mössbauer spectra with attendant reduction in amplitude owing to the fact that the substantial magnetic anisotropy in the x-y plane (The high-spin form of cytochrome P450 monooxygenase exhibits a spectrum of this nature (28)).

For zero-field splitting parameter $|\mathrm{D}|<2 \mathrm{~cm}^{-1}$, the 8.0 T, Mössbauer spectra yield outer features at velocities which are essentially determined by $\mathrm{A}_{0}$, a quantity that should be rather constant for the present species. Even if the D, E/D, and the quadrupole splittings are not well known and multiple species are present, one can match simulations to the outer features of the spectrum and determine the relative amount of high-spin Fe(III) in the sample to within 1-2\%. From simulations such as shown in Figure 7, we found that samples I, II, and III contained 21\%, $20 \%$, and $21 \%$ high-spin Fe(III) from the non-Rieske sites, respectively. The constancy of ferric ion in the three samples implies that the iron of intermediate BZDO $_{P}$ in sample II must be high-spin ferric.

\footnotetext{
${ }^{5}$ The high field signals at $\mathrm{g}=2.01,1.91$, and 1.77 observed in this sample indicate that about $1 \%$ of the Rieske cluster is reduced by an unknown mechanism after 20 minutes. It is likely that this reduced Rieske cluster is paired with an active site devoid of mononuclear iron because the electron would be transferred to the mononuclear center if it were present and no Fe(II) is observed by Mössbauer spectroscopy (see Figure 6B).

${ }^{6} \mathrm{~A}$ sample in which only the mononuclear center was enriched in ${ }^{57} \mathrm{Fe}$ would simplify the fitting in this case. However, the procedure for exchange of the mononuclear iron results in an $\mathrm{Fe}$ (II) center rather than the $\mathrm{Fe}(\mathrm{III})$ center of the ferriBZDO ${ }^{\text {Ox }}$ enzyme used here (see Materials and Methods).
} 
Inspection of the $50 \mathrm{mT}$ Mössbauer spectra of Figure 6B reveals a new, well-defined 6-line spectrum that appears and disappears on the same time scale as $\mathrm{BZDO}_{\mathrm{P}}$ and is thus assigned to this intermediate. As indicated above, a 6-line spectrum will result from the $\mathrm{M}_{\mathrm{S}}= \pm 5 / 2$ doublet of a high-spin ferric species. The 75\% decrease in EPR intensity in the $g_{\text {eff }}=7.4$ to 8.5 region suggests that $\mathrm{BZDO}_{\mathrm{P}}$ should account for approximately $15 \%$ of the total iron in the sample. ${ }^{7}$ The expanded Mössbauer spectrum is shown in Figure 6C. The simulation shown for $\mathrm{BZDO}_{\mathrm{P}}$ (solid line) is drawn to represent $11 \%$ of the total iron and thus matches the predicted BZDO $_{P}$ quite well. The simulation used $\mathrm{D}=-1.5 \mathrm{~cm}^{-1}, \mathrm{E} / \mathrm{D}=0.12$ (the exact value is not critical as long as $\mathrm{E} / \mathrm{D}<0.15), \mathrm{A}_{0} / \mathrm{g}_{\mathrm{n}} \beta_{\mathrm{n}}=-21.3 \mathrm{~T}$, isomer shift $\delta=0.50 \mathrm{~mm} / \mathrm{s}, \Delta \mathrm{E}_{\mathrm{Q}}=0.5 \mathrm{~mm} /$ $\mathrm{s}, \eta=0$ (the value of $\mathrm{D}$ is somewhat arbitrary). We considered several ranges of $\delta$ for $\mathrm{BZDO}_{\mathrm{P}}$, finding $\delta=0.50 \pm 0.02 \mathrm{~mm} / \mathrm{s}$ to be the most satisfactory. The broad absorption features in the Mössbauer spectrum of Figure $6 \mathrm{~B}$ and $\mathrm{C}$ arise from the three species observed in the EPR spectrum with $\mathrm{E} / \mathrm{D}=0.072,0.133$ and $\approx 0.33$ which contribute $\sim 50 \%$ of the Mössbauer absorption of the non-Rieske ferric species.

Initially, we were puzzled by our inability to observe an EPR signal assignable to $\mathrm{BZDO}_{\mathrm{P}}$ since the resonances from an $\mathrm{M}_{\mathrm{S}}= \pm 1 / 2$ state of $\mathrm{E} / \mathrm{D} \sim 0.1$ should be readily observable. On the basis the Mössbauer information, we can now shed some light on this problem. Figure 8 shows a 10 K EPR spectrum of an aliquot of Mössbauer sample II together with a series of spectral simulations of the various species present. In general, the line shapes of high-spin ferric species are dominated by distributions of the rhombicity parameter E/D, and often, adequate simulations can be obtained by assuming that $\mathrm{E} / \mathrm{D}$ is distributed, with variance $\sigma_{\mathrm{E} / \mathrm{D}}$, around a mean value. Accordingly, we have simulated the spectra of the species present in samples I, II, and III by adjusting E/D and $\sigma_{\mathrm{E} / \mathrm{D}}$. The $\mathrm{E} / \mathrm{D}=0.072(\mathrm{D}>0)$ species (major features at $g_{\text {eff }}=$ 7.55 and 5.8), $\mathrm{E} / \mathrm{D}=0.133(\mathrm{D}>0)$ species (major peaks at $g_{\mathrm{eff}}=8.5$ and 5.5) are each simulated separately in Figure 8. Based on these simulations, the $E / D=0.072$ and $E / D=0.126$ species in sample II have a total spin concentration of $60 \mu \mathrm{M}$. For the $\mathrm{E} / \mathrm{D}=0.33$ species, we estimate a spin concentration of $30 \mu \mathrm{M}^{8}$

Where, then, is the signal of $\mathrm{BZDO}_{\mathrm{P}}$, which should represent about $150 \mu \mathrm{M}$ iron according to total iron quantitation from the Mössbauer spectrum described above? The key to this puzzle is the recognition that the temperature dependence of the Mössbauer data show that the 6-line spectrum from the $\mathrm{M}_{S}= \pm 5 / 2$ doublet of $\mathrm{BZDO}_{\mathrm{P}}$ derives from the ground state rather than an excited state. This means that $\mathrm{D}<0$ for intermediate $\mathrm{BZDO}_{\mathrm{P}}$, placing the $\mathrm{M}_{\mathrm{S}}= \pm 1 / 2$ doublet in the highest energy state. Accordingly, the EPR signal from the $\mathrm{M}_{\mathrm{S}}= \pm 5 / 2$ doublet ground state for an E/D 0.1 system would appear at $g=9.98,0.06,0.07$ and would be undetectable due to its low transition probability at $g=9.98$. For example, for $\mathrm{E} / \mathrm{D}=0.1$, the $g_{\mathrm{Z}}=9.9$ feature of the $\mathrm{M}_{\mathrm{S}}= \pm 5 / 2$ doublet $\left(g_{\mathrm{x}}=0.1, g_{\mathrm{y}}=0.1 g_{\mathrm{z}}=9.9\right)$ is ca. 800 -fold less intense than the $g_{\mathrm{y}}=$ 8.0 resonance of the $\mathrm{M}_{\mathrm{S}}= \pm 1 / 2$ doublet $\left(g_{\mathrm{x}}=3.7 g_{\mathrm{y}}=8.0 g_{\mathrm{z}}=1.7\right)(25)$.

Despite the lack of an EPR signal from the ground state, $\mathrm{BZDO}_{\mathrm{P}}$ should give observable signals from the excited $M_{S}= \pm 3 / 2$ and $\pm 1 / 2$ states. The failure to detect these signals easily can be understood by considering their predicted $g$-values. The sharp 6-line Mössbauer spectrum shows that $0<\mathrm{E} / \mathrm{D}<0.15$. For $\mathrm{E} / \mathrm{D}<0.05$ we would expect to observe the strong EPR signal of the $\mathrm{M}_{\mathrm{S}}= \pm 5 / 2$ doublet in the trough between the $g=5.5$ and 8 features, but this is not the case. This places the possible $\mathrm{E} / \mathrm{D}$ value for $\mathrm{BZDO}_{\mathrm{P}}$ between 0.05 and 0.15 , i.e. into a spectral region where the EPR signal of $\mathrm{BZDO}_{\mathrm{P}}$ would have strong overlap with the $\mathrm{E} / \mathrm{D}=0.072$ and

\footnotetext{
${ }^{7}$ The exact amount of species BZDOP depends somewhat on D, because smaller D-values increase the population of the (unresolved) $\mathrm{M}_{\mathrm{S}}= \pm 3 / 2$ and $\pm 1 / 2$ doublets, and thus yield a slightly higher fraction of BZDOP.

8 The line shapes of $g=4.3$ signals are notoriously difficult to simulate. In order to estimate the amount of $g=4.3$ iron in our samples, we have simulated the spectra of all species contributing in the $g=8$ region and subtracted these from the experimental data. This procedure should leave us with the $\mathrm{g}=4.3$ species. Double integration of this signal suggested that the type of iron contributed less than $25 \%$ of the total ferric iron in the enzyme.
} 
0.133 species. Since these species have D $>0$, the $g=7.6$ and 8.5 features are ground state signals and signal $\bullet \mathrm{T}$ has to decline between $2 \mathrm{~K}$ and $10 \mathrm{~K}$ due to population of excited states. Nevertheless, we observed that signal $\bullet \mathrm{T}$ is nearly the same at both temperatures for sample II (Excited states are being populated as witnessed by the observation that resonances in the $\mathrm{g}=$ 5.5-6 region appear upon increasing the temperature). Thus, we conclude that the excited state signals of $\mathrm{BZDO}_{\mathrm{P}}$ from the $\mathrm{M}_{\mathrm{S}}= \pm 1 / 2$ and $\pm 3 / 2$ doublets are underneath those of the other species, and thus it has an E/D of about 0.1 as illustrated in Figure 8; this is in accord with the Mössbauer simulation shown in Figure 6C. Because the EPR signal from this species at $\sim g=$ 8 is from an $M_{S}= \pm 1 / 2$ excited state, it has little intensity at $2 \mathrm{~K}$ and grows in as the temperature increases, thereby buffering the signal intensity in this region. Finally, we note that the simulation of the EPR spectrum of a model complex for a high spin-peroxy complex with a negative zero field splitting and $\mathrm{E} / \mathrm{D}=0.11$ required a $\sigma_{\mathrm{E} / \mathrm{D}} \approx 0.05$ (29). Thus, the excited state signal from $\mathrm{BZDO}_{\mathrm{P}}$ may be much broader and more difficult to detect than is indicated by the simulation shown in Figure 8.

\section{DISCUSSION}

Rieske cis-dihydrodiol forming dioxygenases occupy a unique niche in the oxygenase family because they exhibit characteristics of both monooxygenase and dioxygenase chemical mechanisms. Like many monooxygenases, they require two electrons from NADH supplied by an electron transfer chain for $\mathrm{O}_{2}$ activation in normal catalysis, and they carry out peroxide shunt reactions beginning from the oxidized state. On the other hand, they utilize a 2-His-1carboxylate facial triad mononuclear $\mathrm{Fe}(\mathrm{II})$ center typically found in aromatic ring-cleaving and $\alpha$-keto glutarate $(\alpha \mathrm{KG})$-linked dioxygenases. The latter enzyme class initially catalyzes cleavage of the $\alpha \mathrm{KG}$ cofactor to yield an $\mathrm{Fe}(\mathrm{IV})=\mathrm{O}$ intermediate, which is the most potent oxidizing species observed thus far for the mononuclear non-heme iron class (30). Importantly, none of the non-heme mononuclear iron containing dioxygenases have been shown to stabilize an intermediate equivalent to the formal $\mathrm{Fe}(\mathrm{V})=\mathrm{O}$ species of the heme $(31,32)$ and dinuclear iron cluster-containing monooxygenase classes (33). These observations justify the proposal from other researchers for the mechanism of the Rieske cis-dihydrodiol dioxygenases (see Scheme 1, pathway 3) that invokes reduction by a third electron following formation of an $\mathrm{Fe}$ (III)-peroxo adduct (20). This would yield a species formally at the oxidation level of $\mathrm{Fe}(\mathrm{IV})$ $=\mathrm{O}$ that might subsequently attack aromatic hydrocarbons. In the current study, we show that these proposals are unlikely to be correct in the case of BZDO based on the demonstration that the ferriBZDO ${ }^{\text {ox }}$ peroxide shunt allows formation cis-dihydrodiol product in greater than 50 $\%$ yield from an enzyme devoid of additional reducing equivalents. Thus, if the Rieske dioxygenases utilize a consistent mechanism, the dioxygenase reaction for the Rieske class is likely to occur at the same oxidation level as the most potent monooxygenase reactive species. The time course and kinetic characteristics of the ferriBZDO ${ }^{\text {ox }}$ peroxide shunt reaction also lend new insight into the intermediates of the reaction cycle of this enzyme class and the manner in which the enzyme regulates catalysis. Importantly, we report here that a transient intermediate from the peroxide shunt reaction sequence that disappears as the product complex is formed is high-spin ferric and has unusual spectroscopic characteristics reminiscent of sideon bound peroxo adducts of Fe(III) model complexes. These aspects of Rieske dioxygenase catalysis are discussed here.

\section{Basis for the Low Rate of FerriBZDoox Peroxide Shunt}

The rate constant for the peroxide shunt described here for ferriBZDO ${ }^{\mathrm{ox}}$ is at least 3 orders of magnitude less than the normal turnover rate constant. This is in sharp contrast to the value found for the peroxide shunt of ferroNDO ${ }^{\text {ox }}$, which is similar to that for normal turnover (23). It is possible that this indicates that the chemistry of the ferriBZDO ${ }^{\mathrm{ox}}$ is altered from the normal turnover cycle. However, the fact that cis-dihydroxylation to form the regio- and 
enantiomerically-correct product occurs in the shunt makes this very unlikely. We believe that the low rate constant is due to a manifestation of the regulatory system for the Rieske dioxygenases as described below.

Most peroxide shunt reactions of oxygenase enzymes bridge nonadjacent intermediates of the normal catalytic cycle (see for example 34). Based on our current understanding of the Rieske dioxygenase cycle, this is not the case for the peroxide shunt described here. Scheme 1, pathway 1 or 2 indicates that the normal reaction cycle ends with both metal centers oxidized and product bound. Indeed, we have shown that this is the end point for single turnover reactions beginning from the fully reduced forms of both NDO and $\operatorname{BZDO}(3,18)$. In our proposal for the mechanism developed from these single turnover studies, the next cycle initiates when the mononuclear center is reduced, allowing the product to dissociate and the next substrate to bind. This strong coupling between substrate exchange and reduction of the enzyme ensures that substrate is always present when $\mathrm{O}_{2}$ binds to the mononuclear iron and is activated. This cycle does not contain a state equivalent to ferriBZDO ${ }^{\text {ox }}$, which, based on its EPR spectrum shown in Figure $5 \mathrm{~A}$, does not have substrate or product bound. Thus, the ferriBZDO ${ }^{\text {ox }}$ peroxide shunt starts from a state that is not in the normal reaction cycle. At the completion of the shunt reaction, the enzyme is found in the state equivalent to that at the end of the single turnover cycle, and thus the peroxide shunt rejoins the normal cycle at this point.

The consequence of initiating the shunt at a non-physiological state appears to be a significant decrease in the rate of catalysis, perhaps due to the fact that the binding of substrates must occur with states of the enzyme that are not structurally optimized for the reactions. The oxidation state of the mononuclear iron is the most readily assessed determining factor in the rate of substrate or product exchange. Indeed, the apparent single turnover nature of the peroxide shunt reaction described here is attributed to very slow release of product from the active site with an oxidized mononuclear iron. The Mössbauer spectra of samples from the reaction time course indicate that the mononuclear iron is always in the Fe(III) state. This is consistent with slow substrate binding and the slow substrate release indicated by the stable EPR spectrum of the product complex at the end of the reaction. Two observations reported here support the conclusion that the active site is difficult to access by substrate when the mononuclear iron is oxidized. First, very high concentrations of benzoate and $\mathrm{H}_{2} \mathrm{O}_{2}$ are required for the reaction to occur at a reasonable rate. Second, very little of the $g=4.3$ resonance attributed to the substrate complex of ferriBZDO ${ }^{\text {ox }}$ is observed despite the presence of high benzoate concentrations relative to the $K_{\mathrm{m}}$ value for benzoate in the normal cycle. A better appreciation for the ramifications of the ferric rather than ferrous ion in the active site can be gained by analysis of the reaction time course monitored by EPR, and alternatively, by product formation as described in the following sections.

\section{Analysis of the Reaction Time Course Monitored by EPR and Mössbauer Spectroscopies}

The observed changes that occur in the EPR spectrum of resting ferriBZDO ${ }^{\text {ox }}$ upon exposure to $\mathrm{H}_{2} \mathrm{O}_{2}$ (shown in Figure 5) indicate that $\mathrm{H}_{2} \mathrm{O}_{2}$ and benzoate interact with the mononuclear ferric center in a series of discrete steps. In the initial step of the shunt reaction, a high-spin ferric intermediate $\mathrm{BZDO}_{\mathrm{O}}(\mathrm{E} / \mathrm{D}=0.072)$ forms that is spectrally similar to the resting ferriBZDO ${ }^{\mathrm{ox}}$ and specifically unlike the ferriBZDO ${ }^{\mathrm{ox}}$-benzoate complex. This suggests that $\mathrm{H}_{2} \mathrm{O}_{2}$ rather than benzoate binds in the active site during this initial time period. There are several possibilities for the nature of $\mathrm{BZDO}_{\mathrm{O}}$. Given the small spectral perturbation, it seems most likely that $\mathrm{H}_{2} \mathrm{O}_{2}$ binds near the iron, perturbing its environment. It has been shown by $\mathrm{x}$ ray crystallography that $\mathrm{NO}$ binds in this way (i.e. in the enzyme active site but not to the iron) in the case of fully reduced NDO in the absence of substrate (35). Alternatively, $\mathrm{H}_{2} \mathrm{O}_{2}$ may:

(i) form an end-on complex with the iron as a precursor to a side-on peroxo complex (similar to that structurally characterized for NDO (17)), or (ii) form a side-on complex directly. The 
Mössbauer spectrum of this intermediate shows it to be a high-spin ferric species with $\mathrm{D}>0$. The isomer shift is $0.50 \mathrm{~mm} / \mathrm{s}$, which is typical for $\mathrm{N}$ and $\mathrm{O}$ type ligands from the protein or solvent. These parameters are similar to those of the resting enzyme and unlike those of models for $\mathrm{Fe}(\mathrm{III})$-peroxo complexes $(29,36)$. This suggests that the model for $\mathrm{BZDO}_{\mathrm{O}}$ in which $\mathrm{H}_{2} \mathrm{O}_{2}$ binds near but not to the iron is more likely to be correct.

As $\mathrm{BZDO}_{\mathrm{O}}$ disappears, it is replaced by $\mathrm{BZDO}_{\mathrm{P}}$ which is essentially EPR silent at $2 \mathrm{~K}$, most likely because its ground state has vanishing low transition probability and its zero field splitting parameters, $D$ and $E / D$, are significantly distributed $\left(\sigma_{E / D}\right.$ is perhaps $\left.>0.05\right)$ rendering the excited state signals $(\mathrm{D}<0)$ too broad for detection in the presence of the overlapping E/D $=0.133$ and 0.072 species. The zero-field splittings reflect the effect of spin-orbit coupling between the ground state and a variety of excited states, and thus distributions in $\mathrm{D}$ and $\mathrm{E} / \mathrm{D}$ reflect energy distributions of excited states caused by a heterogeneous ligand environment. Although biological systems with a negative $\mathrm{D}$ are less commonly encountered than those with positive $\mathrm{D}$, several examples are known. Indeed, one of the first to be recognized in a biological system was found in a ring-cleaving dioxygenase, the product complex of protocatechuate 3,4dioxygenase (37). Interestingly, another case in which negative zero field splitting has been reported is in inorganic mononuclear Fe(III) chelate complexes that have a bound side-on peroxo moiety reminiscent of the peroxo complex of NDO $(29,36)$. One of the model complexes had $\mathrm{D}=-1 \mathrm{~cm}^{-1}$ and $\mathrm{E} / \mathrm{D}=0.11$ at $4.2 \mathrm{~K}$, and it yielded a Mössbauer spectrum quite similar in appearance to that of intermediate $\mathrm{BZDO}_{\mathrm{P}}$. However, the isomer shift was found to be $0.61 \mathrm{~mm} / \mathrm{s}$ which significantly larger than that found here for $\mathrm{BZDO}_{\mathrm{P}}$ and more consistent with the values found for other Fe(III)-peroxo complexes.

In order to assess the meaning of the observed isomer shift of $\mathrm{BZDO}_{\mathrm{p}}$, we carried out a series of density functional theory (DFT) calculations. Drawing on the crystallographically established ligand structure of the mononuclear iron site in a peroxy intermediate of the related NDO (17) and the identical sequence alignment of iron ligands BZDO and NDO, we constructed sites having one carboxylate (mono- or bidentate) and two histidyl ligands complemented by a peroxo or hydroperoxo ligand, bound end-on as well as side-on. We then computed the isomer shift for fifteen optimized structures. The structures explored and the calculated shifts, together with computational details, are given in Supplementary Information. The results of these studies are as follows. The $\delta$ values obtained for structures with a peroxo ligand (Figure S3) are larger than $0.64 \mathrm{~mm} / \mathrm{s}$. These values are compatible with the experimentally determined values for the Fe(III)-peroxo model complexes, but they are incompatible with the experimental data for $\mathrm{BZDO}_{\mathrm{P}}$. In contrast, the calculated $\delta$ values were found to be $0.46 \mathrm{~mm} / \mathrm{s}$ for some side-on (Figure S2, III) and end-on (Figure S2, VI) hydroperoxo complexes, which matches the experimental value of $\delta=0.50(2)$ for $\mathrm{BZDO}_{\mathrm{P}}$ within the uncertainties. Replacing a hydroperoxo ligand with a water and hydroxo groups yields some cases with isomer shifts that are compatible with the data as well (see for example Figure S1, $\mathrm{III})$, so the nature of $\mathrm{BZDO}_{\mathrm{P}}$ cannot be definitively assigned from the $\delta$ value. However, complexes with aquo and hydroxo ligands are not known to exhibit negative zero field splitting (one example being ferriBZDO ${ }^{\text {ox }}$ itself, Figure 5A). Moreover, computational studies by Siegbahn and coworkers probing the mechanism of Rieske dioxygenases showed that protonation of the $\mathrm{Fe}(\mathrm{III})$-peroxy intermediate that forms as $\mathrm{O}_{2}$ binds is required to achieve a reactive species (38). Thus, both the catalytic and spectroscopic properties of $\mathrm{BZDO}_{\mathrm{P}}$ are consistent with it being the Fe(III)-hydroperoxo intermediate of the Rieske dioxygenase reaction cycle.

In the final phase of the reaction, product is formed as $\mathrm{BZDO}_{\mathrm{P}}$ decays and the characteristic EPR spectrum of the ferriBZDO ${ }^{\text {ox }}$-product complex is observed. The Mössbauer spectrum of $\mathrm{BZDO}_{\mathrm{P}}$ is also lost and replaced by a high-spin ferric species with $\mathrm{D}>0$. This is consistent with the replacement of a $\mathrm{Fe}(\mathrm{III})$ - hydroperoxo ligand with the oxygens of the cis-dihydrodiol 
product as observed in the X-ray crystal structure for the NDO-product complex (17).

Accordingly, the time frame for this reaction is similar to that observed by directly analyzing product formation in the active site. It is reasonable to assume that once the substrate and peroxide are bound in the proper orientation at the mononuclear iron center, the reaction will proceed rapidly. However, it is unclear from the EPR data whether the observed reaction is slow because substrate is slow to bind to the putative ferriBZDO ${ }^{\text {ox }}-\mathrm{H}_{2} \mathrm{O}_{2}$ complex or whether a slow reorganization of the substrate in the active site after binding is required before the reaction can occur. Some insight into this problem derives from the analysis of the product formation time course.

\section{Analysis of the Reaction Time Course Monitored by Product Formation}

The model for the reaction implied from the EPR time course discussed above includes two intermediate complexes with peroxide binding first and benzoate binding in one or both of the two final steps.

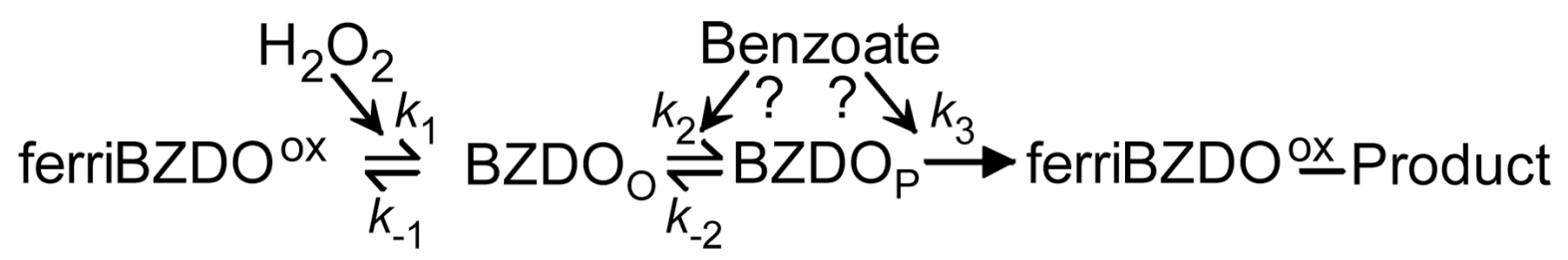

Under the present conditions that: (i) peroxide and benzoate are in large excess over the enzyme, (ii) the product forming step is much slower than the preceding steps, and (iii) the tight product binding forces a single turnover reaction, the product formation reaction would be expected to follow an exponential time course. The solid lines in Figure 1 and Figure 3 are single exponential fits to the data and show that the time course is reasonably well described by this function. In principle, the observed rate constant for the reaction can be obtained from the reciprocal relaxation of the exponential. However, given the length of time required for the reaction, it is possible that other factors such as loss of peroxide due to background catalase activity or degradation of the enzyme due to temperature or $\mathrm{H}_{2} \mathrm{O}_{2}$ exposure may compromise the values obtained. Another approach is to use the initial velocity of product formation to estimate of the apparent first order rate constant. In the current case, good initial velocity values can be obtained due to the slow reaction.

If the substrate binds exclusively in the final step then:

$$
v_{i}=k^{\prime}\left[\mathrm{BZDO}_{\mathrm{p}}\right], \text { where } \mathrm{k}^{\prime} \cong \mathrm{k}_{3}[\text { benzoate }]+k_{-3}
$$

Whereas, if benzoate binds only in the penultimate step:

$$
v_{i} \cong \frac{k_{3}[\text { benzote }]}{K_{D 2}+[\text { benzote }]}+k_{-3}
$$

In each case, $\mathrm{k}_{-3}$ is assumed to be zero since the $\mathrm{O}-\mathrm{O}$ bond cleavage reaction is irreversible. The plot of $v_{\mathrm{i}}$ versus benzoate concentration shown in the Figure 2 is approximately hyperbolic, suggesting that substrate binds to $\mathrm{BZDO}_{\mathrm{O}}$. However, the $K_{\mathrm{D}}$ for this reaction $\left(K_{\mathrm{D} 2} \sim 1 \mathrm{mM}\right)$ shows that the initial complex is weak, and thus, further reorganization of the substrate is likely to occur before catalysis. These changes may be slow, accounting for the slow breakdown of 
$\mathrm{BZDO}_{\mathrm{P}}$. Alternatively, the present results do not rule out substrate-independent conversion of $\mathrm{BZDO}_{\mathrm{O}}$ to $\mathrm{BZDO}_{\mathrm{P}}$ so long as substrate can bind either before or after the conversion. ${ }^{9}$

\section{Structural Basis for Weak $\mathrm{H}_{2} \mathrm{O}_{2}$ Binding}

The requirement for high concentrations of $\mathrm{H}_{2} \mathrm{O}_{2}$ in the ferriBZDO ${ }^{\text {ox }}$ peroxide shunt may also be a consequence of initiating the shunt from a non-physiological state, and thus, be related to regulation. We have observed that the binding of $\mathrm{NO}$ and $\mathrm{O}_{2}$ to the mononuclear iron center is regulated by both substrate binding and the redox state of the Rieske cluster $(3,18)$. If the cluster is oxidized, $\mathrm{O}_{2}$ does not bind to the mononuclear iron, and when it is reduced, substrate must be bound before either $\mathrm{O}_{2}$ or $\mathrm{NO}$ will bind to the iron. Using pulsed ENDOR spectroscopy and deuterium-labeled substrates, we showed that the position of the substrate relative to the mononuclear iron in NDO is sensitive to the redox state of the Rieske cluster $(15,16)$. Recently, the structural basis for these redox-linked conformational changes has been described in work with the Rieske monooxygenase 2-oxoquinoline 8-monooxygenase (13). These studies show that the optimal condition for small molecule binding is when the organic substrate is bound and both metal centers are reduced, i.e. ready for oxygen insertion chemistry to initiate.

Consequently, it is likely that the structural factors that regulate small molecule binding in the normal cycle will bias the active site of ferriBZDO ${ }^{\text {ox }}$ against $\mathrm{H}_{2} \mathrm{O}_{2}$ binding, thereby accounting for the high concentration of $\mathrm{H}_{2} \mathrm{O}_{2}$ required for the shunt.

\section{Comparison of the Peroxide Shunts of FerriBZDOox and FerroBZDOox}

The reduced mononuclear iron of ferroBZDO ${ }^{\text {ox }}$ suggests that rapid exchange of substrate with solution is possible, and thus this enzyme might begin the peroxide shunt with the organic substrate bound. This, in turn, might lead to a faster reaction than observed for ferriBZDO ${ }^{\text {ox }}$. However, it is demonstrated here these reactions occur at about the same rate and have the same requirement for high benzoate and $\mathrm{H}_{2} \mathrm{O}_{2}$ concentrations. One way to reconcile the results follows from the assumption that the cis-dihydroxylation always involves a $\mathrm{Fe}(\mathrm{III})$ -

hydroperoxo intermediate as crystallographically characterized in NDO (17). Thus, substratebound ferroBZDO ${ }^{\text {ox }}$ must first react with $\mathrm{H}_{2} \mathrm{O}_{2}$ in a rapid abortive oxidation cycle that results in an Fe(III) mononuclear site. A similar Fe(II) oxidation pre-cycle occurs in iron-chelate model complexes that carry out cis-dihydroxylation reactions using $\mathrm{H}_{2} \mathrm{O}_{2}$ (39). Subsequent dissociation of the peroxide reduction products and binding of $\mathrm{H}_{2} \mathrm{O}_{2}$ would form the normal reactive intermediate and initiate the shunt reaction, forming $\mathrm{BZDO}_{\mathrm{P}}$ in each case. Since the rate-limiting step follows $\mathrm{BZDO}_{\mathrm{P}}$ formation, little difference in the overall rates of these two peroxide shunt reactions would be observed.

\section{Mechanistic and Regulatory Implications}

From this work, a mechanism for the peroxide shunt reaction and its connections to the normal cycle can be proposed (Scheme 2). The normal cycle begins, following reduction and product release from the previous cycle, with at least the mononuclear iron in the reduced state. This state can readily bind the organic substrate near the iron. The results of MCD and CD studies of NDO and PDO show that substrate binding causes the mononuclear iron to shift from 6 to 5 coordinate so that it is ready to accept $\mathrm{O}_{2}(40,41)$. However, this cannot occur until the Rieske cluster is reduced. Pulsed ENDOR and structural studies of related enzymes suggest that the oxidation of the Rieske cluster shifts the relative positions of the iron and substrate to promote this reaction $(13,15,16)$. As $\mathrm{O}_{2}$ binds, an electron from the iron and one from the Rieske cluster

\footnotetext{
${ }^{9} \mathrm{~A}$ sample of ferriBZDO ${ }^{\text {ox }}$ nearly devoid of benzoate was prepared by gel filtration using benzoate free buffer. This results in loss of $70 \%$ of the mononuclear $\mathrm{Fe}(\mathrm{III})$. The remaining active site iron reacts with $\mathrm{H}_{2} \mathrm{O}_{2}$ to cause loss of the $g=7.7 \mathrm{EPR}$ signal and no subsequent formation of the $g=8.5$ signal from the product complex is observed, as expected. The reaction with $\mathrm{H}_{2} \mathrm{O}_{2}$ differs from that described in this study in that no EPR signal from BZDOO is observed suggesting a different mechanism for reaction with $\mathrm{H}_{2} \mathrm{O}_{2}$. Further studies will be required to characterize this mechanism.
} 
are transferred to generate the reactive peroxo intermediate. The resulting re-oxidation of the Rieske cluster would reverse the conformational change bringing the substrate and activated oxygen species together to promote the cis-dihydroxylation reaction. Finally, reduction of the mononuclear iron would free the product.

The functional ferriBZDO ${ }^{\text {ox }}$ peroxide shunt is consistent with this mechanism in that it suggests that the Fe(III)-hydroperoxo state is capable of cis-dihydroxylation without further one electron reduction. The very slow rate of the reaction supports the overarching regulatory aspects of the proposed cycle in that individual enzymes states seem to be designed to tightly control passage of molecules in and out of the active site and coordinate this flux with electron transfer. As shown in the inner cycle of Scheme 2, in a system where no electron transfer is possible, the incorrect state of the enzyme is forced to bind substrates. Thus, the reaction becomes very slow due to slow substrate binding in the correct position for catalysis, and it is limited to a single turnover. Normal catalysis occurs once the correct intermediate is formed, but the rate of the observed reaction is dominated by the rates of the binding reactions or structural rearrangements that are foreign to the regulatory mechanism of the Rieske dioxygenase.

\section{Supplementary Material}

Refer to Web version on PubMed Central for supplementary material.

\section{ACKNOWLEDGMENT}

We thank Michael Mbughuni for technical assistance and Sarmistha Chakrabarty for valuable discussions.

\section{REFERENCES}

1. Gibson DT, Parales RE. Aromatic hydrocarbon dioxygenases in environmental biotechnology. Curr. Opin. Biotechnol 2000;11:236-243. [PubMed: 10851146]

2. Wackett LP. Mechanism and applications of Rieske non-heme iron dioxygenases. Enzyme Microb. Technol 2002;31:577-587.

3. Wolfe MD, Altier DJ, Stubna A, Popescu CV, Münck E, Lipscomb JD. Benzoate 1,2-dioxygenase from Pseudomonas putida: Single turnover kinetics and regulation of a two-component Rieske dioxygenase. Biochemistry 2002;41:9611-9626. [PubMed: 12135383]

4. Reiner AM, Hegeman GD. Metabolism of benzoic acid by bacteria. Accumulation of (-)-3,5cyclohexadiene-1,2-diol-1-carboxylic acid by mutant strain of Alcaligenes eutrophus. Biochemistry 1971;10:2530-2536. [PubMed: 4326771]

5. Jenkins GN, Ribbons DW, Widdowson DA, Slawin AMZ, Williams DJ. Synthetic application of biotransformations: absolute stereochemistry and Diels-Alder reactions of the (1S,2R)-1,2dihydroxycyclohexa-3,5-diene-1-carboxylic acid from Pseudomonas putida. J. Chem. Soc., Perkin Trans 1995;1:2647-2655.

6. Yamaguchi M, Fujisawa H. Purification and characterization of an oxygenase component in benzoate 1,2-dioxygenase system from Pseudomonas arvilla C-1. J. Biol. Chem 1980;255:5058-5063. [PubMed: 7372624]

7. Karlsson A, Beharry ZM, Eby DM, Coulter ED, Neidle EL, Kurtz DM Jr, Eklund H, Ramaswamy S. X-ray crystal structure of benzoate 1,2-dioxygenase reductase from Acinetobacter sp. strain ADP1. J. Mol. Biol 2002;318:261-272. [PubMed: 12051836]

8. Gassner G, Wang L, Batie C, Ballou DP. Reaction of phthalate dioxygenase reductase with NADH and NAD: kinetic and spectral characterization of intermediates. Biochemistry 1994;33:12184-12193. [PubMed: 7522555]

9. Gassner GT, Ludwig ML, Gatti DL, Correll CC, Ballou DP. Structure and mechanism of the ironsulfur flavoprotein phthalate dioxygenase reductase. FASEB J 1995;9:1411-1418. [PubMed: 7589982] 
10. Kauppi B, Lee K, Carredano E, Parales RE, Gibson DT, Eklund H, Ramaswamy S. Structure of an aromatic-ring-hydroxylating dioxygenase-naphthalene 1,2-dioxygenase. Structure 1998;6:571-586. [PubMed: 9634695]

11. Furusawa Y, Nagarajan V, Tanokura M, Masai E, Fukuda M, Senda T. Crystal structure of the terminal oxygenase component of biphenyl dioxygenase derived from Rhodococcus sp. strain RHA1. J. Mol. Biol 2004;342:1041-1052. [PubMed: 15342255]

12. Friemann R, Ivkovic-Jensen MM, Lessner DJ, Yu C-L, Gibson DT, Parales RE, Eklund H, Ramaswamy S. Structural insight into the dioxygenation of nitroarene compounds: the crystal structure of nitrobenzene dioxygenase. J. Mol. Biol 2005;348:1139-1151. [PubMed: 15854650]

13. Martins BM, Svetlitchnaia T, Dobbek H. 2-Oxoquinoline 8-monooxygenase oxygenase component: active site modulation by Rieske-[2Fe-2S] center oxidation/reduction. Structure 2005;13:817-824. [PubMed: 15893671]

14. Dong X, Fushinobu S, Fukuda E, Terada T, Nakamura S, Shimizu K, Nojiri H, Omori T, Shoun H, Wakagi T. Crystal structure of the terminal oxygenase component of cumene dioxygenase from Pseudomonas fluorescens IP01. J. Bacteriol 2005;187:2483-2490. [PubMed: 15774891]

15. Yang T-C, Wolfe MD, Neibergall MB, Mekmouche Y, Lipscomb JD, Hoffman BM. Substrate binding to NO-ferro-naphthalene 1,2-dioxygenase studied by high-resolution Q-band pulsed ${ }^{2} \mathrm{H}$-ENDOR spectroscopy. J. Am. Chem. Soc 2003;125:7056-7066. [PubMed: 12783560]

16. Yang T-C, Wolfe MD, Neibergall MB, Mekmouche Y, Lipscomb JD, Hoffman BM. Modulation of substrate binding to naphthalene 1,2-dioxygenase by Rieske cluster reduction/oxidation. J. Am. Chem. Soc 2003;125:2034-2035. [PubMed: 12590516]

17. Karlsson A, Parales JV, Parales RE, Gibson DT, Eklund H, Ramaswamy S. Crystal structure of naphthalene dioxygenase: side-on binding of dioxygen to iron. Science 2003;299:1039-1042. [PubMed: 12586937]

18. Wolfe MD, Parales JV, Gibson DT, Lipscomb JD. Single turnover chemistry and regulation of $\mathrm{O}_{2}$ activation by the oxygenase component of naphthalene 1,2-dioxygenase. J. Biol. Chem 2001;276:1945-1953. [PubMed: 11056161]

19. Tarasev M, Rhames F, Ballou DP. Rates of the phthalate dioxygenase reaction with oxygen are dramatically increased by interactions with phthalate and phthalate oxygenase reductase. Biochemistry 2004;43:12799-12808. [PubMed: 15461452]

20. Tarasev M, Ballou DP. Chemistry of the catalytic conversion of phthalate into its cis-dihydrodiol during the reaction of oxygen with the reduced form of phthalate dioxygenase. Biochemistry 2005;44:6197-6207. [PubMed: 15835907]

21. Batie CJ, LaHaie E, Ballou DP. Purification and characterization of phthalate oxygenase and phthalate oxygenase reductase from Pseudomonas cepacia. J. Biol. Chem 1987;262:1510-1518. [PubMed: 3805038]

22. Pinto A, Tarasev M, Ballou DP. Substitutions of the "bridging" aspartate 178 result in profound changes in the reactivity of the Rieske center of phthalate dioxygenase. Biochemistry 2006;45:90329041. [PubMed: 16866348]

23. Wolfe MD, Lipscomb JD. Hydrogen peroxide-coupled cis-diol formation catalyzed by naphthalene 1,2-dioxygenase. J. Biol. Chem 2003;278:829-835. [PubMed: 12403773]

24. Myers AG, Siegel DR, Buzard DJ, Charest MG. Synthesis of a broad array of highly functionalized. enantiomerically pure cyclohexane carboxylic acid derivatives by microbial dihydroxylation of benzoic acid and subsequent oxidative and rearrangement reactions, Org. Lett 2001;3:2923-2926.

25. Aasa R, Vänngård T. EPR Signal intensity and powder shapes: a reexamination. J. Magn. Reson 1975;19:308-315.

26. Wickman HH, Klein MP, Shirley DA. Paramagnetic resonance of $\mathrm{Fe}^{3+}$ in polycrystalline ferrichrome A. J. Chem. Phys 1965;42:2113-2117.

27. Münck, E. Aspects of 57Fe Mössbauer spectroscopy. In: Que, L., Jr, editor. Physical Methods in Bioinorganic Chemistry. Sausalito, CA: University Science Books; 2000. p. 287-319.

28. Sharrock M, Münck E, Debrunner PG, Marshall V, Lipscomb JD, Gunsalus IC. Mössbauer studies of cytochrome P-450 cam. Biochemistry 1973;12:258-265. [PubMed: 4682999]

29. Roelfes G, Vrajmasu V, Chen K, Ho R, Y. N., Rohde J-U, Zondervan C, La Crois, R., M., Schudde E, P., Lutz M, Spek A, L., Hage R, Feringa B, L., Münck E, Que L Jr. End-on and side-on peroxo 
derivatives of non-heme iron complexes with pentadentate ligands: models for putative intermediates in biological iron/dioxygen chemistry. Inorg. Chem 2003;42:2639-2653. [PubMed: 12691572]

30. Price JC, Barr EW, Tirupati B, Bollinger JM Jr, Krebs C. The first direct characterization of a highvalent iron intermediate in the reaction of an a-ketoglutarate-dependent dioxygenase: A high-spin $\mathrm{Fe}$ (IV) complex in taurine alpha-ketoglutarate dioxygenase (TauD) from Escherichia coli. Biochemistry 2003;42:7497-7508. [PubMed: 12809506]

31. McMurry, TJ.; Groves, JT. Metalloporphyrin models for cytochrome P-450, in. In: Ortiz de Montellano, PR., editor. tCytochrome P-450 Structure, Mechanism, and Biochemistry. New York: Plenum Press; 1986. p. 1-28.

32. Groves JT. High-valent iron in chemical and biological oxidations. J. Inorg. Biochem 2006;100:434447. [PubMed: 16516297]

33. Lee S-K, Fox BG, Froland WA, Lipscomb JD, Münck E. A transient intermediate of the methane

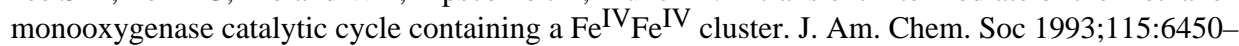
6451.

34. Wallar BJ, Lipscomb JD. Dioxygen activation by enzymes containing binuclear non-heme iron clusters. Chem. Rev 1996;96:2625-2657. [PubMed: 11848839]

35. Karlsson A, Parales JV, Parales RE, Gibson DT, Eklund H, Ramaswamy S. NO binding to naphthalene dioxygenase. J. Biol. Inorg. Chem 2005;10:483-489. [PubMed: 15942729]

36. Neese F, Solomon EI. Detailed spectroscopic and theoretical studies on $\left[\mathrm{Fe}(\mathrm{EDTA})\left(\mathrm{O}_{2}\right)\right]^{3-}$ : electronic structure of the side-on ferric-peroxide bond and its relevance to reactivity. J. Am. Chem. Soc 1998;120:12829-12848.

37. Que L Jr, Lipscomb JD, Zimmermann R, Münck E, Orme-Johnson NR, Orme-Johnson WH. Mössbauer and EPR spectroscopy of protocatechuate 3,4-dioxygenase from Pseudomonas aeruginosa. Biochim. Biophys. Acta 1976;452:320-334. [PubMed: 188463]

38. Bassan A, Blomberg MRA, Siegbahn PEM. A theoretical study of the cis-dihydroxylation mechanism in naphthalene 1,2-dioxygenase. J. Biol. Inorg. Chem 2004;9:439-452. [PubMed: 15042436]

39. Chen K, Costas M, Kim J, Tipton AK, Que L Jr. Olefin cis-dihydroxylation versus epoxidation by non-heme iron catalysts: two faces of an FeIII-OOH coin. J. Am. Chem. Soc 2002;124:3026-3035. [PubMed: 11902894]

40. Gassner GT, Ballou DP, Landrum GA, Whittaker JW. Magnetic circular dichroism studies on the mononuclear ferrous active site of phthalate dioxygenase from Pseudomonas cepacia show a change of ligation state on substrate binding. Biochemistry 1993;32:4820-4825. [PubMed: 7683910]

41. Pavel EG, Martins LJ, Ellis WR Jr, Solomon EI. Magnetic circular dichroism studies of exogenous ligand and substrate binding to the non-heme ferrous active site in phthalate dioxygenase. Chem. Biol 1994;1:173-183. [PubMed: 9383387] 


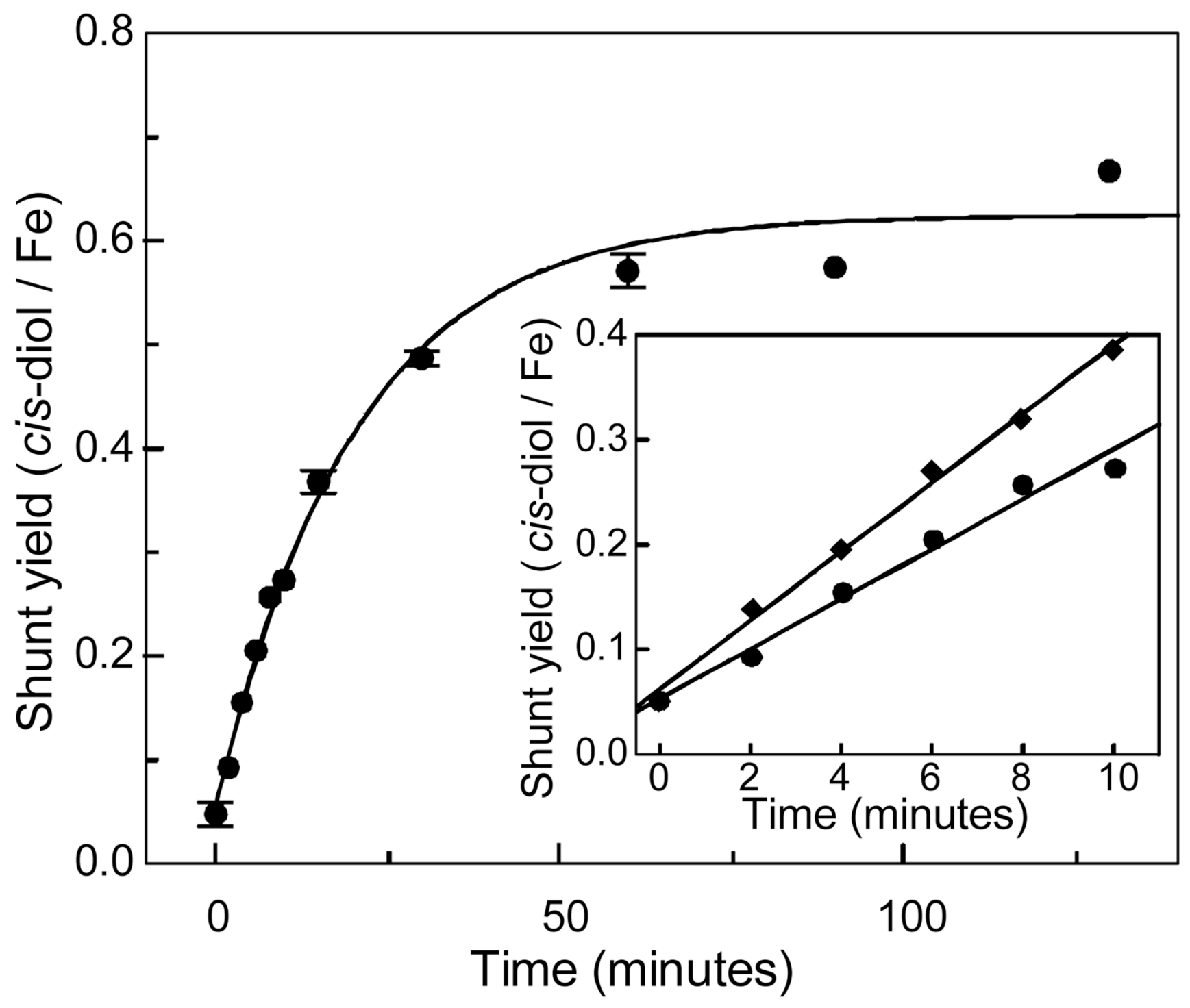

FIGURE 1.

Time course of product formation by the $\mathrm{H}_{2} \mathrm{O}_{2}$ shunt reaction of ferriBZDO ${ }^{\text {ox }}$. The product yield per occupied mononuclear iron site is plotted versus time for the ferriBZDO ${ }^{\text {ox }} \mathrm{H}_{2} \mathrm{O}_{2}$ shunt reaction. Reaction conditions were as described in the Materials and Methods section except that the benzoate concentration after mixing was $1 \mathrm{mM}$ (circles). Data points with three or more repeats are shown with error bars while those with two repeats are shown as an average. The solid line is an exponential fit to the data. Inset: The first 10 minutes of the shunt reaction are plotted for benzoate concentrations after mixing of $1 \mathrm{mM}$ (circles) and $10 \mathrm{mM}$ (diamonds). The solid lines are linear fits to the data. 


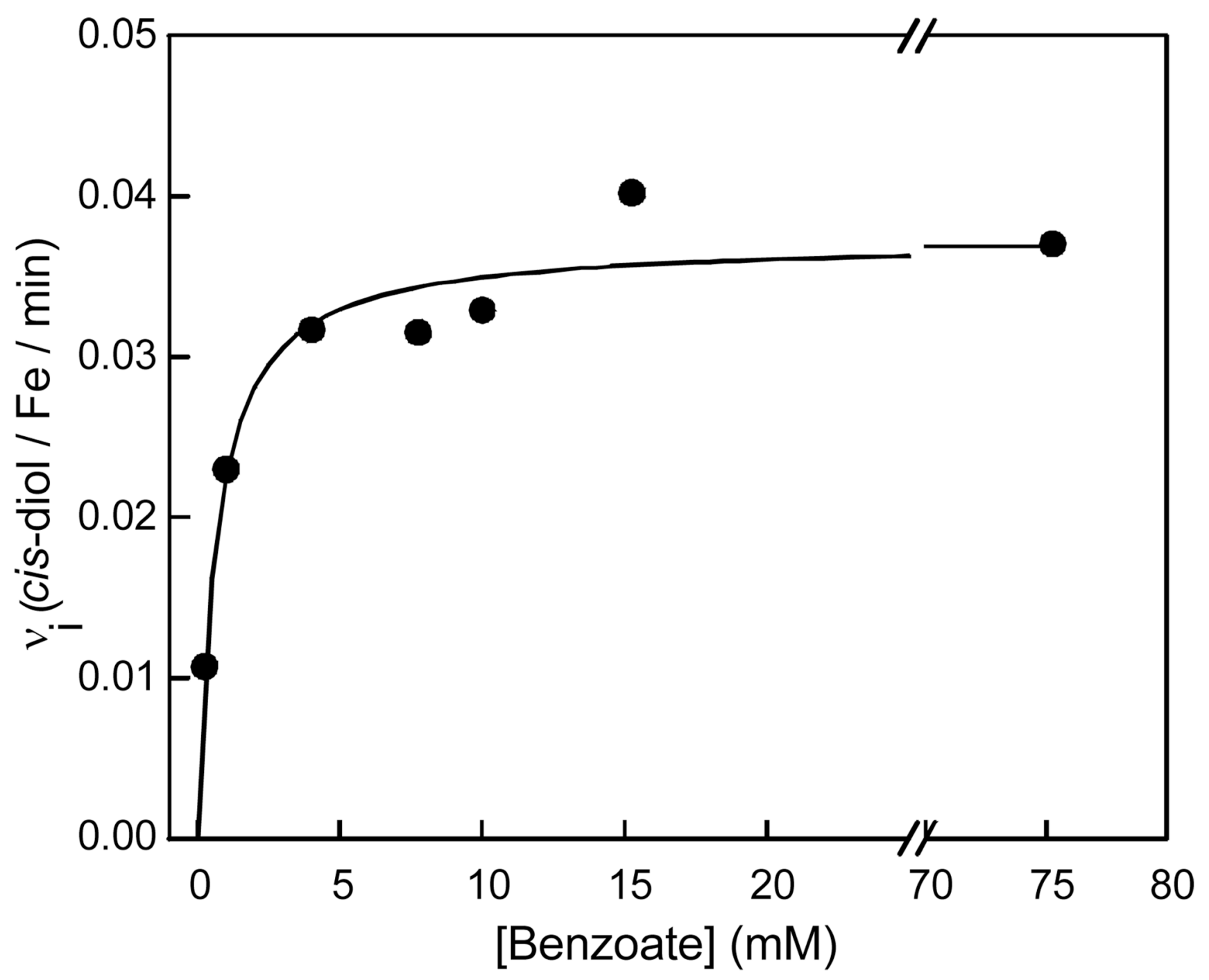

FIGURE 2.

Effect of benzoate concentration on the initial rate of the peroxide shunt reaction. The initial velocity of the ferriBZDO ${ }^{o x} \mathrm{H}_{2} \mathrm{O}_{2}$ shunt reaction is plotted versus the benzoate concentration. Initial velocities were determined from a linear fit of the first 10 minutes of each progress curve (see Figure 1, inset). Reaction conditions are described in the Materials and Methods section with the benzoate concentrations indicated in the figure. 


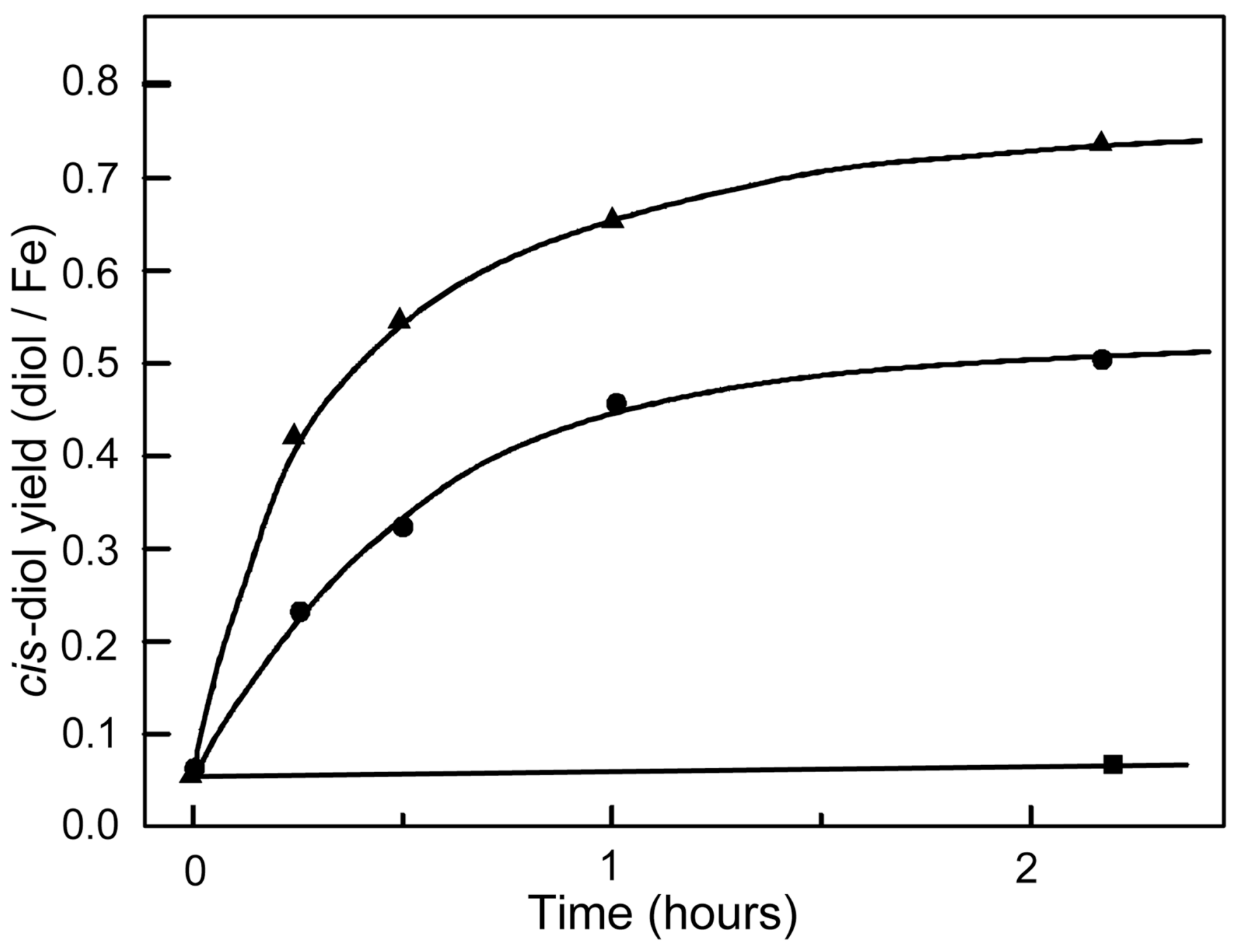

FIGURE 3.

Effect of $\mathrm{H}_{2} \mathrm{O}_{2}$ concentration on the rate and extent of the peroxide shunt reaction. The reaction conditions are described in the Materials and Methods section, except the $\mathrm{H}_{2} \mathrm{O}_{2}$ concentration was either $0 \mathrm{mM}$ (squares), $10 \mathrm{mM}$ (circles), or $50 \mathrm{mM}$ (triangles) after mixing. 


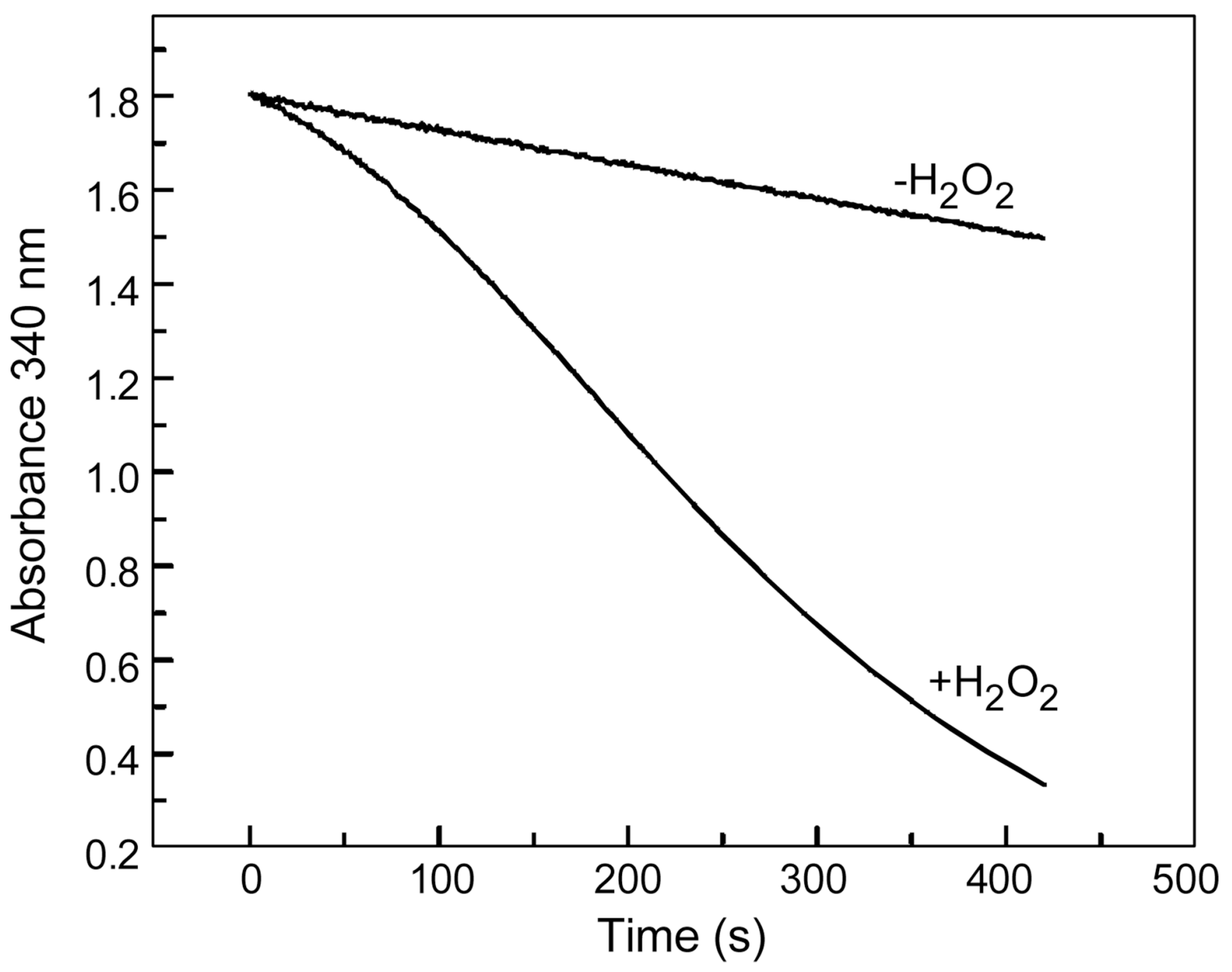

FIGURE 4.

Effect of $\mathrm{H}_{2} \mathrm{O}_{2}$ on NADH consumption by BZDR. NADH consumption was monitored by $\mathrm{UV}$-visible spectroscopy at $340 \mathrm{~nm}$. Reaction conditions: $\mathrm{T}=23{ }^{\circ} \mathrm{C}, 2 \mu \mathrm{M}$ BZDR, $300 \mu \mathrm{M}$ $\mathrm{NADH}$ in $0.1 \mathrm{M}$ MOPS pH 6.9, $0.1 \mathrm{M} \mathrm{NaCl} ; 0 \mathrm{mM} \mathrm{H}_{2} \mathrm{O}_{2}$ (upper trace) or $1 \mathrm{mM} \mathrm{H}_{2} \mathrm{O}_{2}$ (lower trace). 


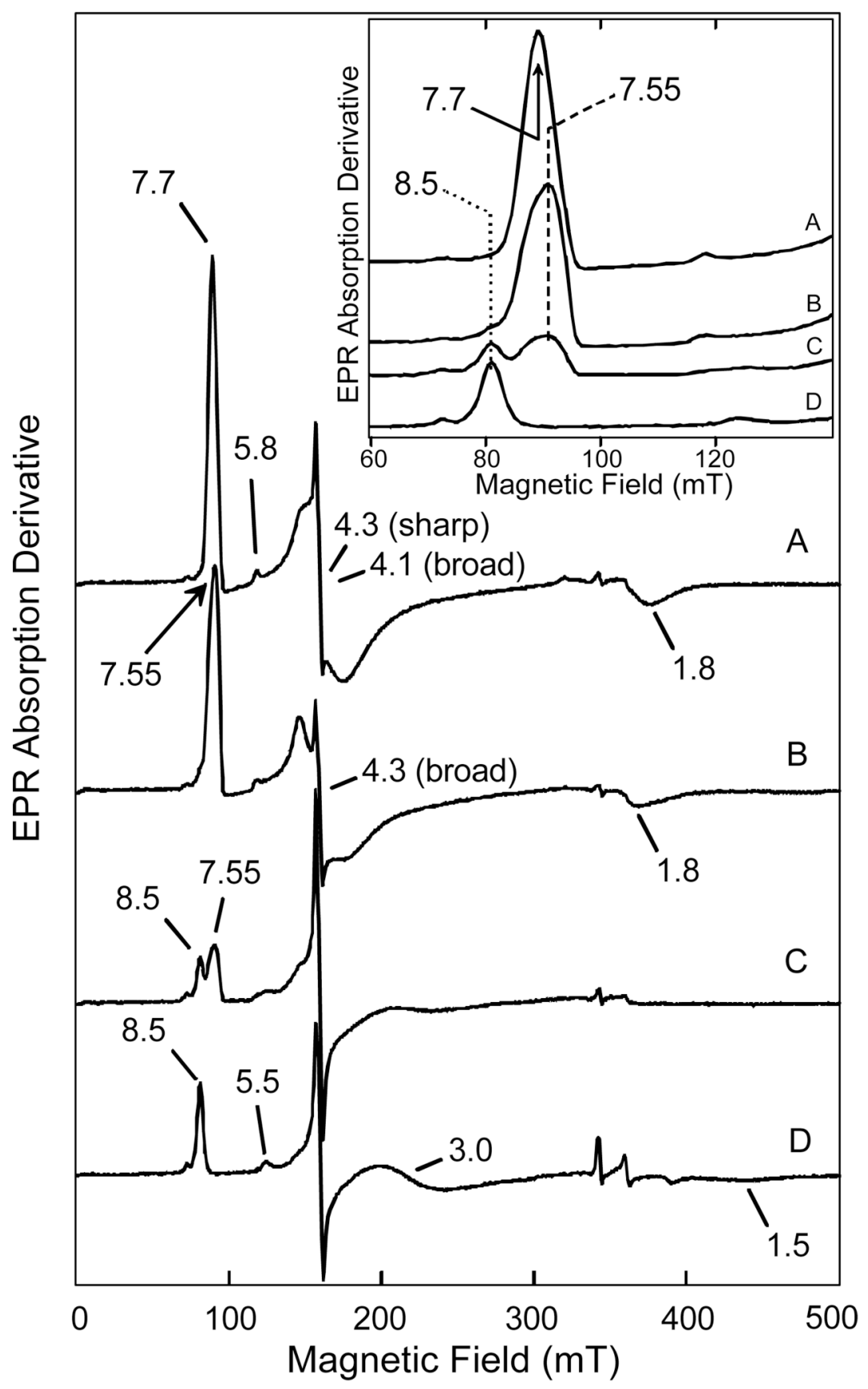

FIGURE 5.

EPR spectra of $\mathrm{BZDO}_{\mathrm{I}}$ throughout the peroxide shunt turnover cycle. Sample (A) contains 0 $\mathrm{mM} \mathrm{H}_{2} \mathrm{O}_{2}$; samples (B-D) contain $50 \mathrm{mM} \mathrm{H}_{2} \mathrm{O}_{2}$. Samples were reacted for 0 (A), 0.5 (B), 4.0 (C), or 20 minutes (D). Other reactant concentrations (after mixing) were as follows: $0.7 \mathrm{mM}$ BZDO $(\alpha \beta), 15 \mathrm{mM}$ benzoate, $10 \mathrm{mM} \mathrm{KCN}, 50 \mathrm{mM}$ MOPS pH 6.9. 


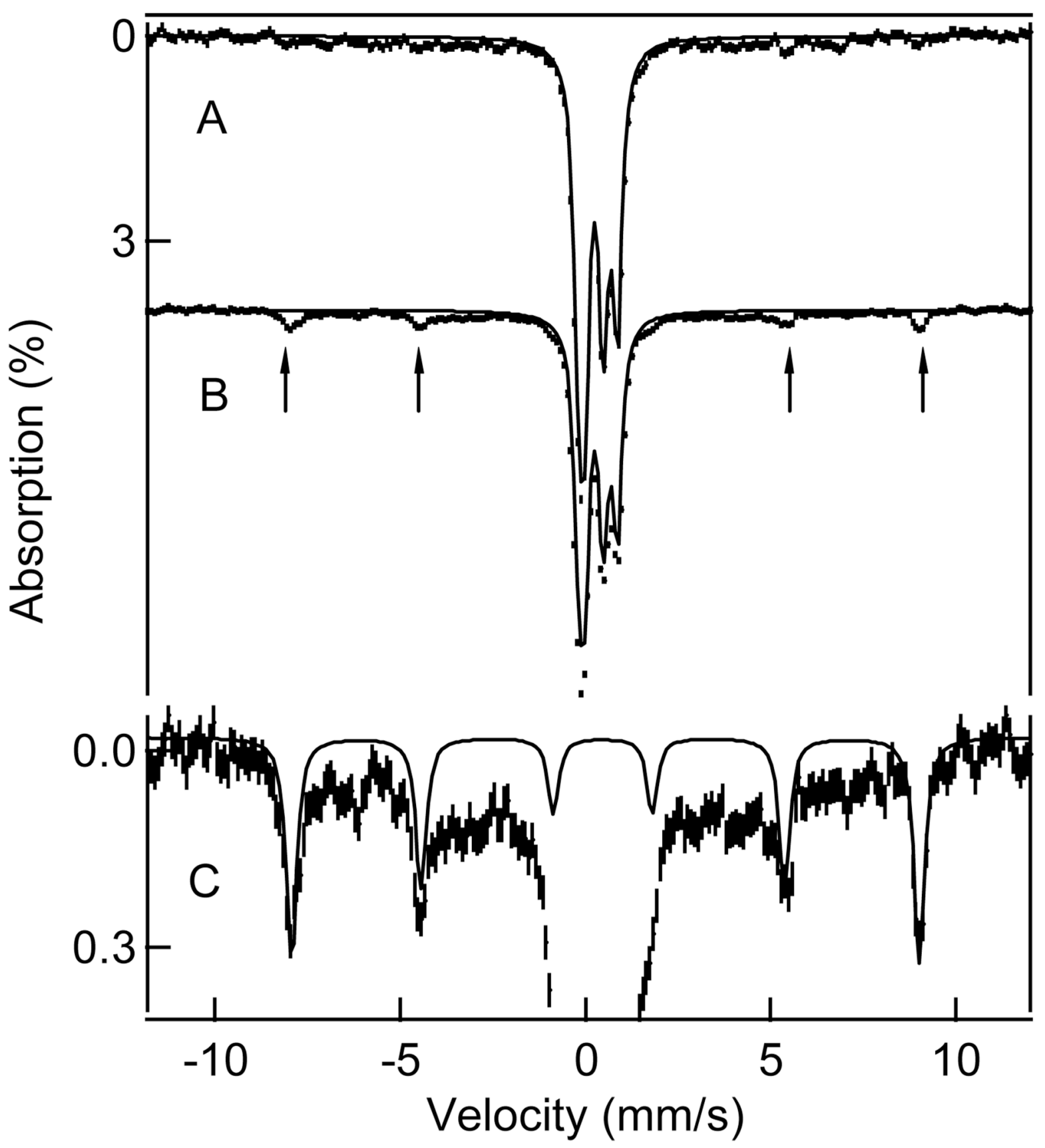

FIGURE 6. 4.2 K

Mössbauer spectra, recorded in a $50 \mathrm{mT}$ parallel field, of samples from a peroxide shunt reaction in progress. Samples were frozen $30 \mathrm{~s}$ (sample I) (A) and 4 min (sample II) (B) after addition of peroxide. Solid lines in (A) and (B) are a simulation of the spectrum of the Rieske center. Arrows in (B) point at four absorption lines assigned to intermediate BZDOP. (C) shows an enlarged segment of the spectrum of (B). The solid line is a spectral simulation, drawn to represent $11 \%$ of the iron in the sample, to an $\mathrm{S}=5 / 2$ spin Hamiltonian for $\mathrm{D}=-1.5 \mathrm{~cm}^{-1}$, E/ $\mathrm{D}=0.12, \mathrm{~A}_{0} / \mathrm{g}_{\mathrm{n}} \beta_{\mathrm{n}}=-21.3 \mathrm{~T}, \delta=0.50 \mathrm{~mm} / \mathrm{s}, \Delta \mathrm{E}_{\mathrm{Q}}=0.5 \mathrm{~mm} / \mathrm{s}, \eta=0$. 


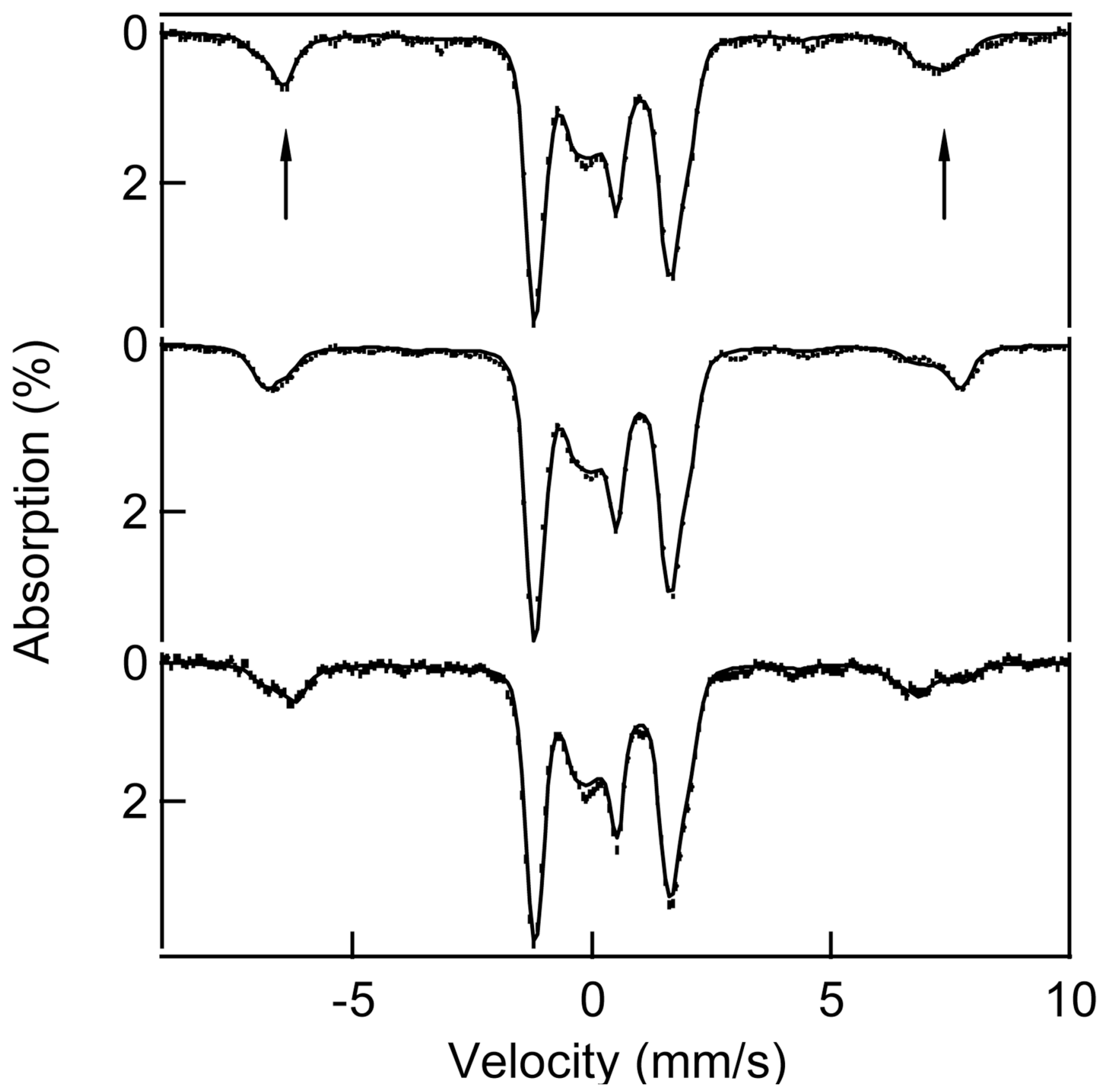

FIGURE 7.

8.0 T Mössbauer spectra of samples I (top), II (middle), and III (bottom) from a peroxide shunt reaction in progress. The arrows in the top spectrum point to the high-velocity features of highspin Fe(III) sites. The spectral areas under these features are a good measure of the amount of mononuclear high-spin ferric ions present. The solid lines are spectral simulations representing all iron in the sample. The total amount of mononuclear Fe(III) is essentially the same (to within better than $1 \%$ ) in the three samples. 


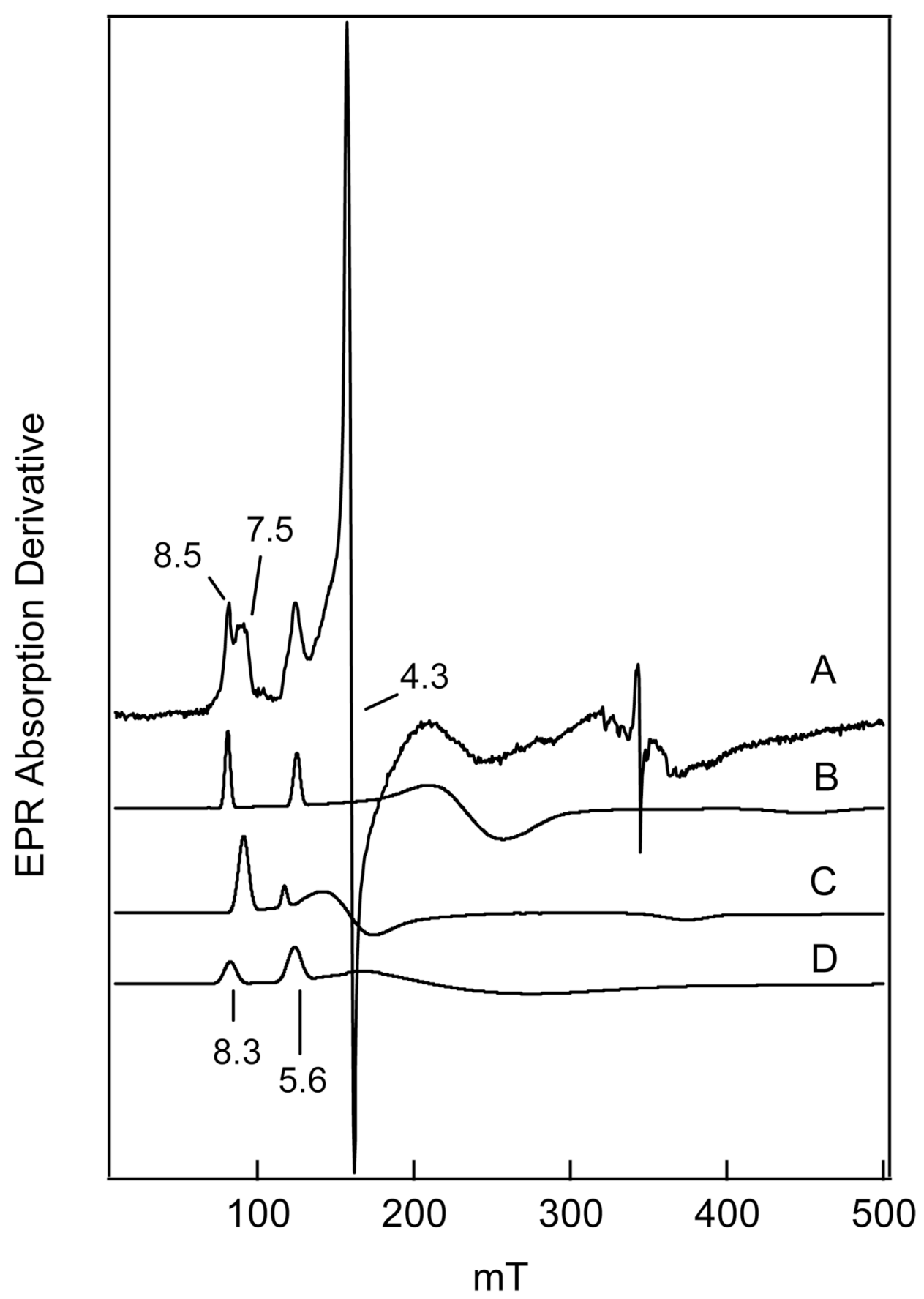

FIGURE 8.

(A) X-band EPR spectrum of sample II recorded at $\mathrm{T}=13 \mathrm{~K}$ under non-saturating conditions. Conditions: microwave power, $0.2 \mathrm{~mW}$; modulation amplitude, $1.0 \mathrm{mT}$ at $100 \mathrm{kHz}$. (B) Spectral simulation of the $\mathrm{E} / \mathrm{D}=0.133$ species, using $\mathrm{D}=2.5 \mathrm{~cm}^{-1}$ and $\sigma_{\mathrm{E} / \mathrm{D}}=0.012$. (C) Simulation of the $E / D=0.072$ species at the same concentration, using $D=1.7 \mathrm{~cm}^{-1}$ and $\sigma_{\mathrm{E} / \mathrm{D}}=0.014$. (D) Simulation of the putative spectrum of $\mathrm{BZDO}_{\mathrm{p}}$ at twice the concentration of (B) using $\mathrm{D}=-1.5 \mathrm{~cm}^{-1}, \mathrm{E} / \mathrm{D}=0.12$, and $\sigma_{\mathrm{E} / \mathrm{D}}=0.03$. For this species, $\sigma_{\mathrm{E} / \mathrm{D}}$ is probably larger than 0.05 , a value that would broaden the lines sufficiently to make the species nearly 
undetectable even at a concentration of ca. $60^{-}-70 \mu \mathrm{M}$. The spin concentration of the combined $\mathrm{E} / \mathrm{D}=0.133$ and 0.072 species accounts for ca. $60 \mu \mathrm{M}$. 


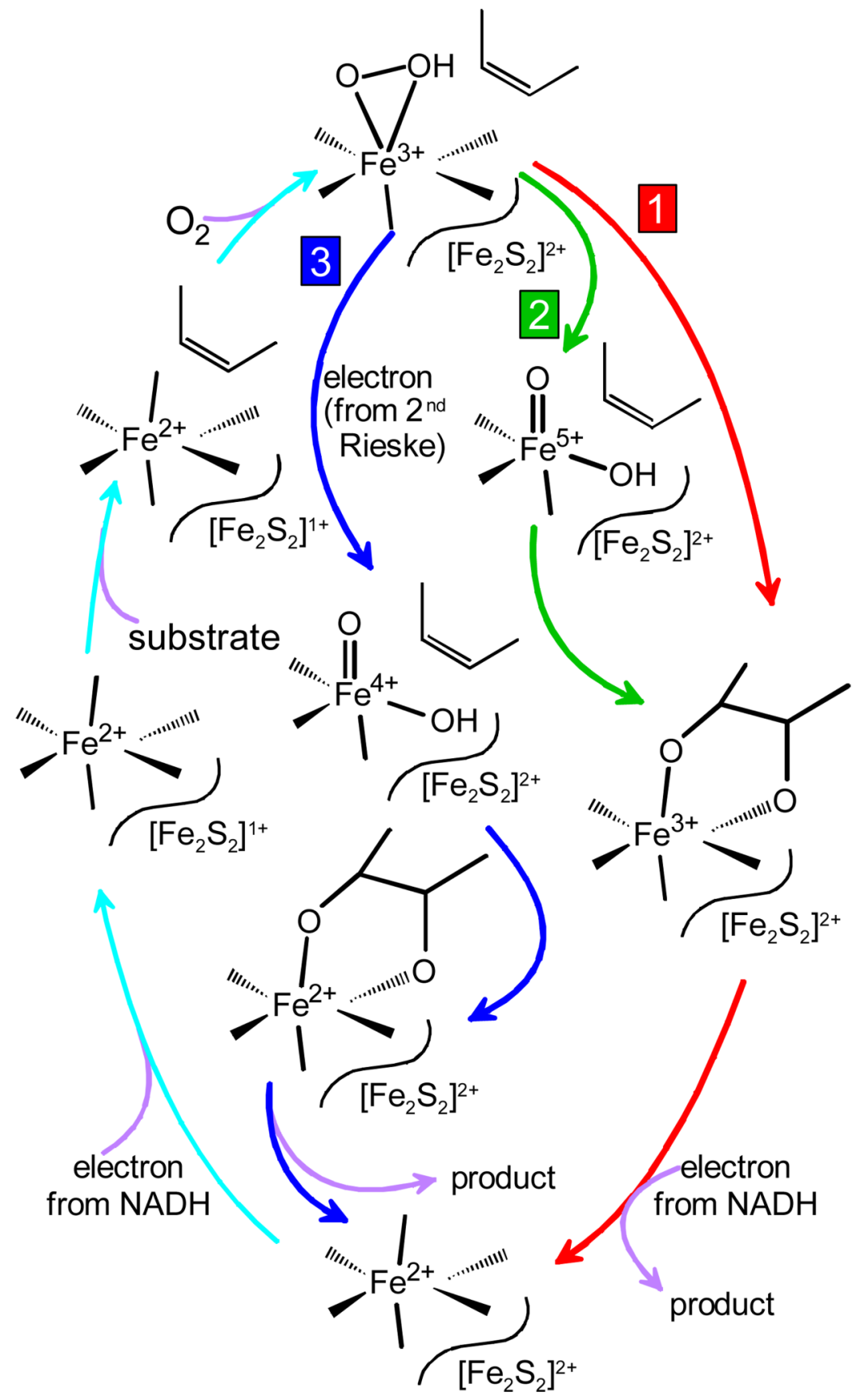

Scheme 1.

Alternative Proposals for the Reaction Cycle of Benzoate 1,2-Dioxygenase 


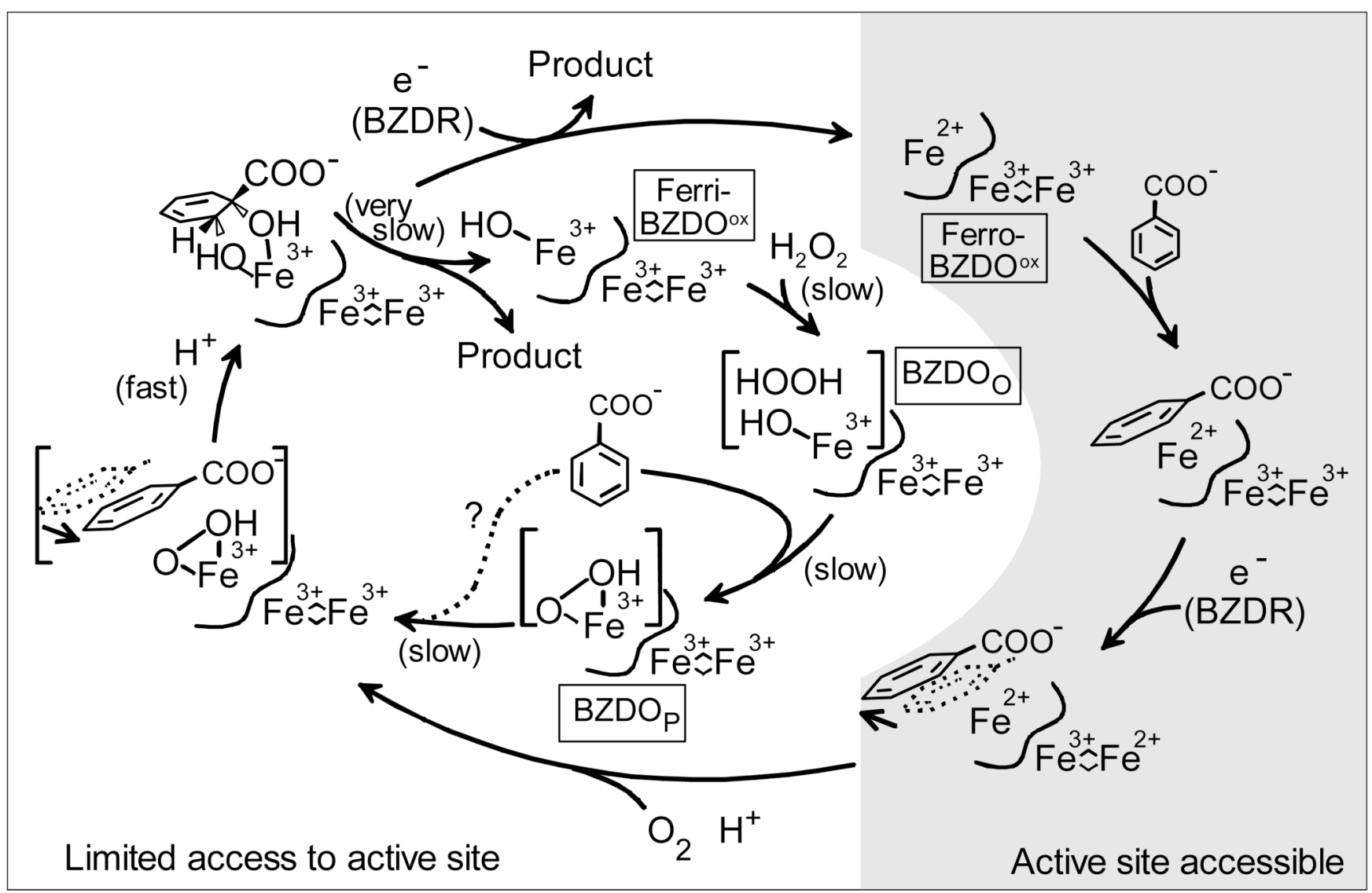

Scheme 2.

Current Mechanistic Proposal for the Chemical and Regulatory Mechanisms of Benzoate 1,2Dioxygenase The peroxide shunt of ferriBZDO ${ }^{\text {ox }}$ in represented in the inner cycle.

FerriBZDO $^{\text {ox }}$ may be generated during purification by slow release of product from the product complex after the supply of reducing equivalents is exhausted. 
Table 1

Product Yield from Peroxide Shunt Systems ${ }^{a}$

\begin{tabular}{|c|c|c|}
\hline system & & product yield \\
\hline & cis-diol / $\alpha \beta$ & cis-diol / mononuclear $\mathrm{Fe}^{b}$ \\
\hline ferroNDO ${ }^{\mathrm{ox}}+30 \mathrm{mM} \mathrm{H}_{2} \mathrm{O}_{2}^{c}$ & $0.6(0.3)$ & $0.8(0.2)$ \\
\hline ferroBZDO $^{\text {ox }}+50 \mathrm{mM} \mathrm{H}_{2} \mathrm{O}_{2}$ & $0.4(0.2)$ & $0.6(0.2)$ \\
\hline ferriBZDO $^{\mathrm{ox}}+50 \mathrm{mM} \mathrm{H}_{2} \mathrm{O}_{2}$ & $0.5(0.3)$ & $0.7(0.2)^{d}$ \\
\hline \multicolumn{3}{|c|}{${ }^{a}$ Conditions: see Materials and Methods. } \\
\hline \multicolumn{3}{|c|}{$b_{\text {Typically }} 50-75 \%$ of the mononuclear iron sites are occupied. } \\
\hline \multicolumn{3}{|c|}{${ }^{c}$ Data from ref. (23) and additional experiments. } \\
\hline
\end{tabular}




\section{Table 2}

Effects of Conditions on the Product Yield from BZDO Peroxide Shunt Systems ${ }^{a}$

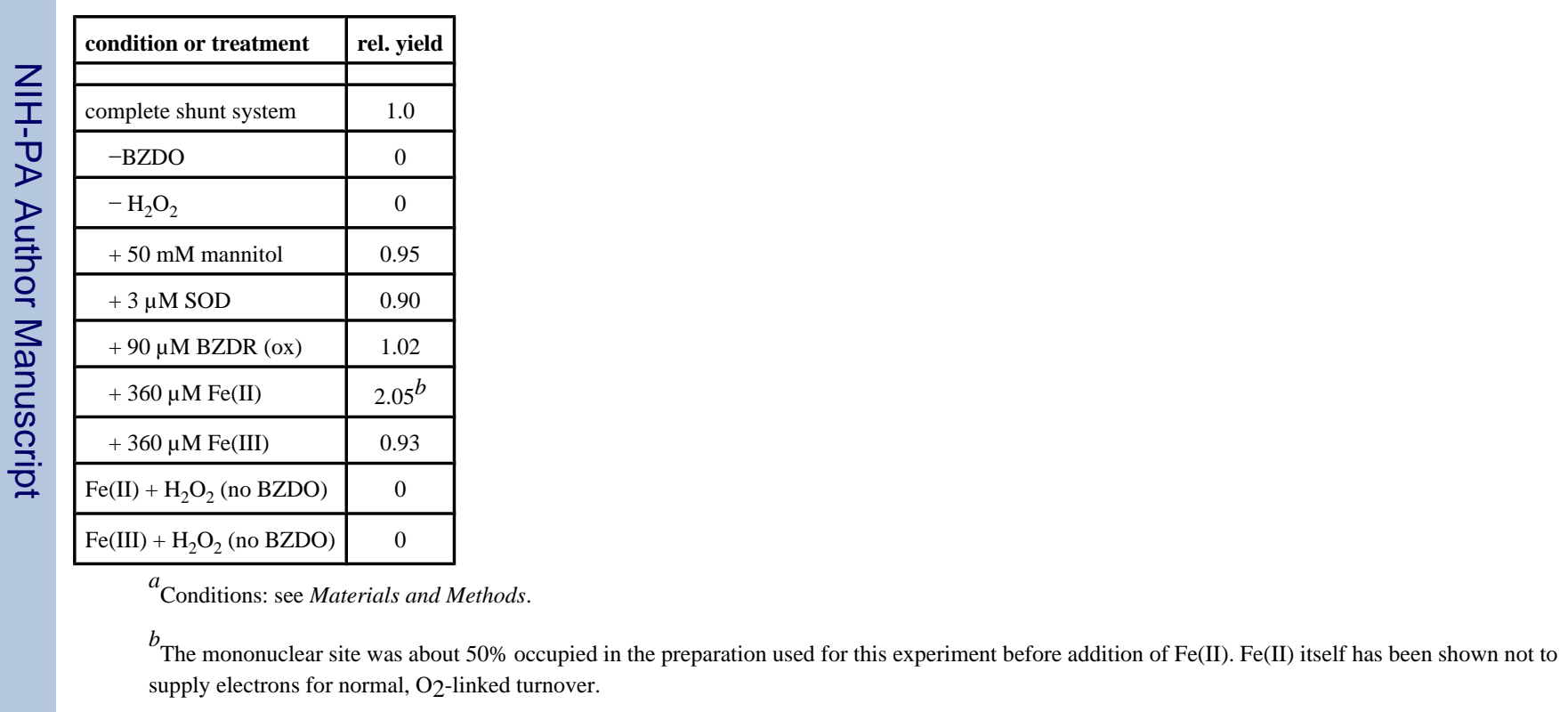

